\title{
Factors associated with postoperative atrial fibrillation and other adverse events after cardiac surgery
}

\author{
Emmanuel Akintoye, MD, MPH, ${ }^{\mathrm{a}}$ Frank Sellke, MD, ${ }^{\mathrm{b}}$ Roberto Marchioli, MD, ${ }^{\mathrm{c}}$ Luigi Tavazzi, MD, ${ }^{\mathrm{d}}$ and \\ Dariush Mozaffarian, MD, DrPH
}

\section{ABSTRACT}

Objective: The study objective was to evaluate the impact of various surgical characteristics and practices on the risk of postoperative atrial fibrillation and other adverse outcomes after cardiac surgery.

Methods: By using the prospectively collected data of patients who underwent cardiac surgery in 28 centers across the United States, Italy, and Argentina, the details of surgery characteristics were collected for each patient and the outcomes, including postoperative atrial fibrillation, major adverse cardiovascular events, and mortality. These were evaluated via multivariable-adjusted models.

Results: In 1462 patients, a total of 460 cases of postoperative atrial fibrillation, 33 major adverse cardiovascular events, 23 cases of 30-day mortality, and 46 cases of 1-year mortality occurred. We found that type of surgery and cardiopulmonary bypass use predicted the occurrence of postoperative atrial fibrillation. Compared with coronary artery bypass grafting alone, there was a higher risk of postoperative atrial fibrillation with valvular surgery alone (odds ratio, 1.4; 95\% confidence interval, 1.1-1.9), and the risk was even higher with concomitant valvular and coronary artery bypass grafting surgery (odds ratio, 1.8; 95\% confidence interval, 1.2-2.7). Compared with no bypass, use of cardiopulmonary bypass was associated with higher risk of postoperative atrial fibrillation (odds ratio, 2.4; 95\% confidence interval, 1.7-3.5), but there were significant age and sex differences of the impact of bypass use among patients undergoing coronary artery bypass grafting $(P$ for interaction $=.04)$. In addition, compared with spontaneous return of rhythm, ventricular pacing was associated with a higher risk of major adverse cardiovascular events (odds ratio, 5.0; 95\% confidence interval, 1.4-18), whereas concomitant coronary artery bypass grafting and valvular surgery was associated with a higher risk of 30-day mortality (hazard ratio, 4.3; 95\% confidence interval, 1.2-14) compared with coronary artery bypass grafting alone. Occurrence of postoperative atrial fibrillation was associated with greater length of stay and 1-year mortality (hazard ratio, 2.2; 95\% confidence interval, 1.2-3.9).

Conclusions: In this multicenter trial, we identified specific adverse outcomes that are associated with concomitant valvular and coronary artery bypass graft surgery, cardiopulmonary bypass, ventricular pacing, and occurrence of postoperative atrial fibrillation. (J Thorac Cardiovasc Surg 2018;155:242-51)

\footnotetext{
From the a Department of Internal Medicine, Wayne State University School of Medicine, Detroit, Mich; ${ }^{b}$ Department of Cardiothoracic Surgery, Alpert Medical School, Brown University, Providence, RI; ${ }^{\mathrm{c}}$ Department of Hematology and Oncology, Therapeutic Science and Strategy Unit, Quintiles, Milan, Italy; ${ }^{\mathrm{d}}$ Department of Cardiology and LTTA Centre, University of Ferrara, Ferrara, Italy; Maria Cecilia Hospital- GVM Care \& Research, and E.S. Health Science Foundation, Cotignola, Italy; and ${ }^{\mathrm{e}}$ Friedman School of Nutrition Science \& Policy, Tufts University, Boston, Mass.

The parent OPERA trial was supported by the National Institutes of Health (RC2HL101816), GlaxoSmithKline, Sigma Tau, and Pronova BioPharma. No additional funding was received for this post hoc analysis.
}

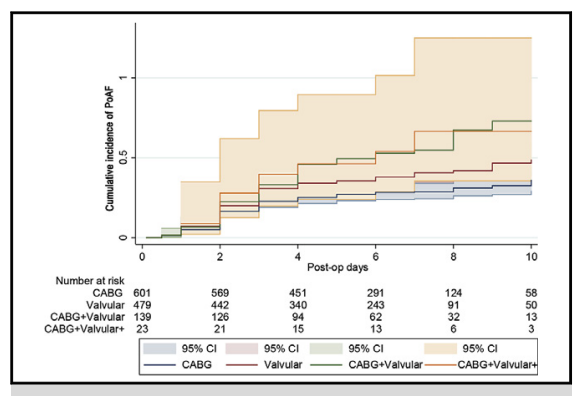

Cumulative incidence of PoAF according to type of surgery.

\section{Central Message}

Concomitant valvular and CABG surgery, cardiopulmonary bypass, and ventricular pacing are associated with adverse outcomes, including postoperative atrial fibrillation, MACE, and mortality.

\section{Perspective}

This study identified that concomitant valve and $\mathrm{CABG}$ surgery, cardiopulmonary bypass use, and ventricular pacing are high-risk procedures that are associated with adverse outcomes, including postoperative atrial fibrillation, MACE, and mortality.

See Editorial Commentaries pages 252 and 254.

See Editorial page 236.

\footnotetext{
Clinical Trial Registration: URL: Clinicaltrials.gov Unique identifier: NCT00970489.

Received for publication Jan 17, 2017; revisions received June 13, 2017; accepted for publication July 19, 2017; available ahead of print Sept 8, 2017.

Address for reprints: Emmanuel Akintoye, MD, MPH, Department of Internal Medicine, Wayne State University School of Medicine, 4201 St Antoine UHC 2E, Detroit, MI 48201 (E-mail: eakintoy@med.wayne.edu). $0022-5223 / \$ 36.00$

Copyright $(2017$ by The American Association for Thoracic Surgery http://dx.doi.org/10.1016/j.jtcvs.2017.07.063
} 

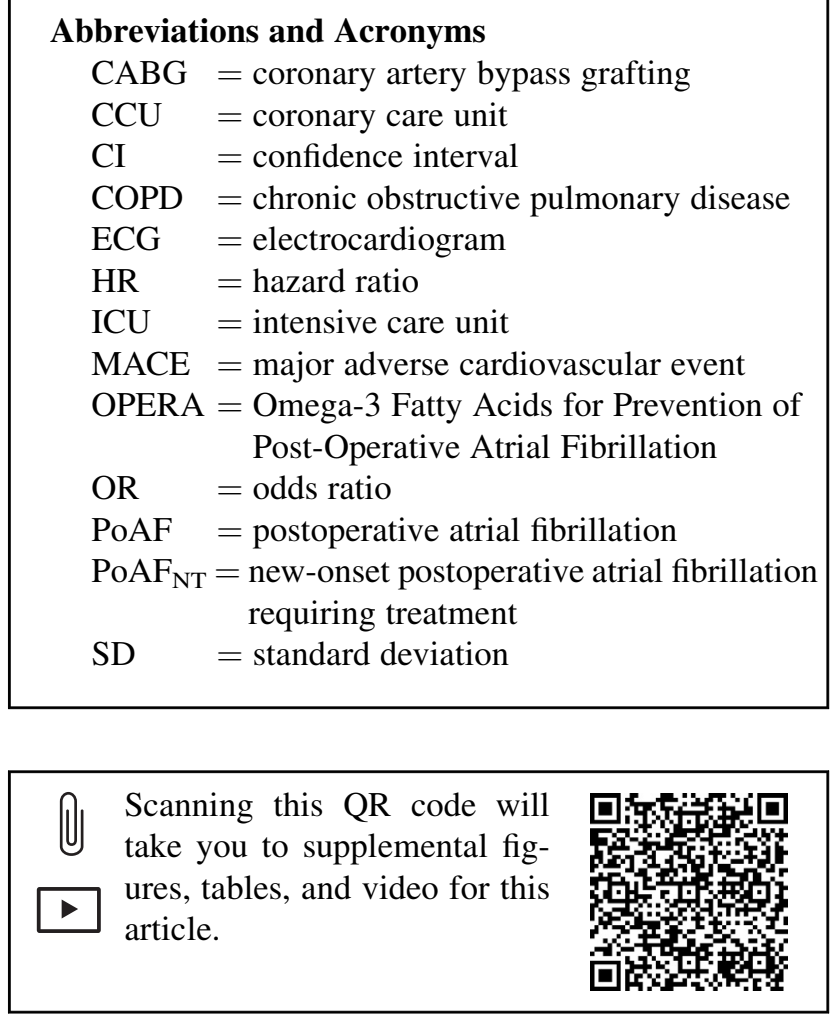

Postoperative atrial fibrillation (PoAF) or flutter complicates approximately one third of cases of cardiac surgery and is associated with major adverse consequences, including prolonged in-hospital length of stay, increased health care costs, and increased rehospitalization rates. ${ }^{1-3}$

Cardiac surgery is associated with direct and indirect myocardial injuries that are potential stimuli for adverse atrial remodeling and may increase arrhythmic risk. .,2,4,5 $^{-1}$ Thus, it is unsurprising that high rates of atrial fibrillation occur after cardiac surgery. However, there are scant contemporary data on how various surgery characteristics contribute to this risk, limiting the development of effective predictive and preventive measures.

Most earlier studies evaluating the risk of PoAF focused mainly on patient factors. ${ }^{6-11}$ In addition, the few studies evaluating the surgical characteristics in relation to PoAF were restricted in the scope of surgery types (eg, most only evaluated coronary artery bypass graft [CABG] procedures) and patient populations (eg, single country), limiting the generalizability of their findings. ${ }^{12-15}$ Furthermore, many of these analyses were performed using historical data, limiting relevance to modern surgical procedures.

Because of these issues, evidence on surgery characteristics is lacking in most risk-prediction tools for PoAF, ${ }^{7,16,17}$ representing an important missed opportunity to improve patient care and outcomes. A better understanding of how surgery characteristics affect the risk of PoAF will help inform appropriate patient screening and counseling, as well as guidelines for surgical practice.

We performed a detailed investigation of how surgery characteristics relate to the incidence of PoAF using the prospectively collected data of the Omega-3 Fatty Acids for Prevention of Post-Operative Atrial Fibrillation (OPERA) trial, a large, multinational study of contemporary patients undergoing cardiac surgery that showed perioperative fish oil supplementation did not significantly affect the incidence of PoAF. In addition, we evaluated the impact of PoAF and other surgical and patient characteristics on inhospital major adverse cardiovascular events (MACE), postoperative mortality, and resource use to provide evidence on how these characteristics may relate to other common complications in a contemporary surgical population.

\section{MATERIALS AND METHODS \\ Study Design and Patients}

This study was performed using the prospectively collected database of the OPERA trial, ${ }^{18}$ a randomized, double-blind, placebo-controlled trial that showed that perioperative fish oil supplementation did not significantly affect the incidence of PoAF. The design and primary results have been reported in detail. ${ }^{18,19}$ Briefly, 1516 patients scheduled for cardiac surgery were enrolled across 28 centers in 3 countries (United States, Italy, and Argentina) between 2010 and 2012. Broad inclusion criteria captured a generalizable patient population: age 18 years or more; scheduled for cardiac surgery (any combination of CABG, valve surgery, or other cardiac surgery opening the pericardium); and sinus rhythm at enrollment. Exclusion criteria were regular use ( $\geq 3$ days/week) of fish oil within the prior 4 weeks; known allergy to fish oil or olive oil (placebo); unable or unwilling to provide informed written consent; being currently pregnant; or having an existing or a planned cardiac transplant or use of ventricular assist device. The study was approved by the human subjects committees of all participating institutions, and all patients provided written informed consent. The present investigation used available data on all patients $(n=1462)$ who underwent cardiac surgery after enrollment.

\section{Surgery Characteristics}

Cardiac surgeries and postoperative care were performed in the OPERA trial to approximate real-world clinical practices, and no rigid protocol control that deviated from norm was used, for example, treating physicians could use beta-blockers or amiodarone as part of their usual clinical practices. With the use of standardized electronic data-collection sheets, details of surgery characteristics were prospectively collected for all patients in the OPERA trial. Examples of evaluated characteristics included type of surgery (eg, CABG, valvular surgery, various combinations), types and numbers of bypass grafts and target valves, access procedure (eg, open, mini thoracotomy), bypass characteristics (cardiopulmonary bypass, offpump vs on-pump CABG, duration of pump time, duration of crossclamp time), cardioplegia use, and method of return of rhythm after surgery (spontaneous vs assisted). The assisted method of rhythm return includes defibrillation, atrial pacing, and ventricular pacing. In patients requiring the assisted method of return of rhythm, the last method used immediately before the return of rhythm was defined as the method of rhythm return irrespective of other methods that had been tried.

\section{End Points}

The primary end point for this trial was the occurrence of PoAF of at least 30 seconds duration and documented by rhythm strip or 12-lead 
electrocardiogram (ECG), evaluated from the time of cardiac surgery to hospital discharge or postoperative day 10, whichever occurred first. All patients were evaluated by telemetry monitoring in the postoperative period, and daily ECGs also were encouraged. All potential episodes of PoAF were reviewed and adjudicated by a centralized events committee of cardiac electrophysiologists. Secondary end points included new-onset PoAF requiring treatment $\left(\mathrm{PoAF}_{\mathrm{NT}}\right), \mathrm{MACE}$ (ie, myocardial infarction, stroke, or cardiovascular death), and 30-day and 1-year mortality. In addition, we evaluated the impact of PoAF on postoperative mortality and resource use, as defined by intensive care unit (ICU)/coronary care unit (CCU) length of stay and total hospital stay. Details of each end point are provided in Table E1.

\section{Covariates}

Standardized data were collected on demographics, cardiovascular risk factors, major comorbidities, medical and surgical history, anthropometric measurements, medication use (outpatient and inpatient), echocardiographic evaluation, and baseline laboratory indices. Daily follow-up and discharge information were recorded.

\section{Statistical Analysis}

To compare baseline characteristics between patients with and without PoAF, we used the chi-square test for categoric variable. For the continuous variables, normality of distribution was evaluated graphically and tested using the Skewness/Kurtosis test. Normally distributed variables were reported as mean ( \pm standard deviation $[\mathrm{SD}])$ and compared between the 2 groups using unpaired $t$ test. On the other hand, non-normally distributed variables were reported as median with interquartile range and compared between the 2 groups using Wilcoxon rank-sum test. The association between surgery characteristics and incidence of PoAF was assessed in 2 stages via logistic regression. First, we evaluated each surgery characteristics separately in a multivariable model that adjusted for covariates consistently associated with the risk of PoAF in the past, including age, sex, race, history of atrial fibrillation, left atrial diameter, and chronic obstructive pulmonary disease (COPD). Additional evaluated covariates included country of enrollment, body mass index, smoking status, hypertension, prevalent heart failure, prevalent renal failure, prior percutaneous coronary intervention, baseline use of antiarrhythmic, and perioperative use of beta-blockers and statins, each considered for inclusion using a backward selection procedure $(P$ exclusion $=.20, P$ inclusion $=.10)$. In addition, we evaluated for potential interactions (effect modification) between each surgery characteristic and clinically relevant factors, including age, sex, and race. Interactions were evaluated by introducing a multiplicative interaction term for the continuous form of age in the model; for the binary form within categories of age ( $\geq 65$ years vs $<65$ years), sex, and race; and evaluating the significance of this term using the Wald test in the multivariable model. Second, to identify independent predictors of PoAF, we combined all surgery characteristics (evaluated among the entire patient population) and covariates that showed some univariate association with PoAF (ie, with $P<.2)$ in a logistic prediction model. However, variables evaluated only among subgroups of the patient population, for example, off-pump (vs on-pump) CABG (which was evaluated only among patients undergoing $\mathrm{CABG}$ ), were not considered for inclusion in this prediction model because including them would restrict the analysis to only patients within the subgroup. The overall predictive ability of the model was assessed using the C-statistic and interactions were tested as described. The association between surgery characteristics and other secondary end points were similarly evaluated using logistic regression and covariates adjustments as described. The cumulative incidence of surgery characteristics that independently predicted primary or secondary end points were further displayed via the Kaplan-Meier method.

To assess the impact of surgical characteristics and PoAF on MACE, mortality, and hospital length of stay, we used logistic regression (for MACE), Cox proportional hazard model (for mortality), and linear regression (for length of stay), with PoAF as 1 independent variable in a multivariable model. Proportional hazard assumption of the Cox model was tested via Schoenfeld residuals, whereas linearity and homoscedasticity assumptions of the linear regression model were evaluated via plot of the model residuals with the predictor variables and fitted lines, respectively. Covariate data were available in most patients, with rare missing values for body mass index $(0.7 \%)$, baseline antiarrhythmic medication use $(3.8 \%)$, perioperative beta-blocker $(3.8 \%)$ and statin $(1.1 \%)$ use, and method for rhythm return $(3.5 \%)$, and more commonly missing data for preoperative left atrial diameter $(32 \%)$. For each of these, we performed multivariate multiple imputations using available information from other variables (ie, age, sex, race, history of atrial fibrillation, COPD, smoking status, hypertension, heart failure, renal failure, prior percutaneous coronary intervention, incident PoAF, mortality, and length of stay) to account for the missing values. Multiple imputations were performed using the chained equations procedure via linear regression for body mass index and left atrial diameter, logistic regression for beta-blocker and antiarrhythmic use, and multinomial regression for rhythm return method. ${ }^{20}$ For a sensitivity analysis, we performed complete case analysis for all end points using only nonmissing covariates. All analyses were performed using STATA 14 (StataCorp, LP, College Station, Tex), 2-tailed $\alpha=0.05$.

\section{RESULTS}

Of the 1462 patients who underwent cardiac surgery in the OPERA trial, mean (SD) participant age was 64 (13) years, $72 \%$ were men, and cardiovascular risk factors were common among the participants (Table 1). CABG and valvular surgery were the most common types of cardiac surgery performed; 601 of the patients underwent isolated CABG, 479 patients underwent isolated valvular surgery, 139 patients underwent combination of CABG and valvular surgery, and 23 patients underwent a combination of CABG, valvular, and at least 1 other procedure. Among all cardiac surgeries performed, cardiopulmonary bypass was used in 1252 patients $(86 \%$ ), in whom $97 \%$ involved the use of cardioplegic solutions. Other details of surgery and postoperative medications are shown in Table E2. During follow-up, a total of 460 cases of PoAF (31\% of subjects), 356 cases of $\mathrm{PoAF}_{\mathrm{NT}}(24 \%), 33$ cases of MACE $(2.3 \%), 23$ 30-day deaths (1.6\%), and 461 -year deaths $(3.1 \%)$ occurred. The mean (SD) ICU/CCU length-of-stay was 2.7 (2.2) days, and total hospital stay was 10 (5.8) days.

\section{Surgical and Patient Characteristics and Risk of Postoperative Atrial Fibrillation}

The incidence of PoAF increased from the day of surgery to a peak on postoperative day 2 and declined steadily thereafter (Figure E1). When we evaluated the association between each surgery characteristic and incidence of PoAF, 4 major surgery characteristics - type of surgery, use of cardiopulmonary bypass, cardioplegia, and off-pump (vs onpump) $\mathrm{CABG}$ - were significantly associated with the risk of PoAF (in separate analysis) (Table 2). For example, compared with $\mathrm{CABG}$ alone, there was a higher risk of PoAF among patients undergoing valvular surgery alone (odds ratio [OR], 1.4; 95\% CI, 1.1-1.9) and even higher 
TABLE 1. Baseline characteristics of $\mathbf{1 4 6 2}$ patients undergoing cardiac surgery in the OPERA trial, overall and according to subsequent postoperative atrial fibrillation

\begin{tabular}{|c|c|c|c|c|}
\hline Characteristics & Total $(n=1462)$ & No PoAF $(n=1002)$ & $\operatorname{PoAF}(n=460)$ & $P$ value \\
\hline Age, mean (SD), y & $64(13)$ & $62(13)$ & $69(10)$ & $<.001$ \\
\hline Men, No. $(\%)$ & $1066(73)$ & $729(72)$ & $337(73)$ & .53 \\
\hline White race, No. $(\%)$ & $1401(96)$ & $955(95)$ & $446(97)$ & .10 \\
\hline Country, No. $(\%)$ & & & & .59 \\
\hline Italy & $735(50)$ & $494(49)$ & $241(52)$ & \\
\hline United States & $423(29)$ & $294(30)$ & $129(28)$ & \\
\hline Argentina & $306(21)$ & $216(21)$ & $90(20)$ & \\
\hline BMI, median (IQR), $\mathrm{kg} / \mathrm{m}^{2}$ & $27(6.0)$ & $27(6.1)$ & $28(5.5)$ & .05 \\
\hline Waist circumference, median (IQR), $\mathrm{cm}$ & $98(15)$ & $97(15)$ & $100(13)$ & .10 \\
\hline Diabetes mellitus, No. (\%) & $381(26)$ & $258(26)$ & $123(27)$ & .63 \\
\hline Hypertension, No. (\%) & $1093(75)$ & $718(71)$ & $375(82)$ & $<.001$ \\
\hline Current smoking, No. (\%) & $188(13)$ & $147(15)$ & $41(9)$ & .002 \\
\hline Dyslipidemia, No. (\%) & $909(62)$ & $621(62)$ & $288(63)$ & .63 \\
\hline Total cholesterol, $\mathrm{mg} / \mathrm{dL}$ mean (SD) & $176(42)$ & $177(42)$ & $174(42)$ & .29 \\
\hline Congestive heart failure, No. $(\%)$ & $395(27)$ & $259(26)$ & $136(30)$ & .18 \\
\hline Chronic renal failure, No. $(\%)$ & $88(6.0)$ & $47(4.7)$ & $41(8.9)$ & .02 \\
\hline History of Afib, No. (\%) & $102(7.2)$ & $50(5.1)$ & $52(12)$ & $<.001$ \\
\hline COPD, No. $(\%)$ & $163(11)$ & $101(10)$ & $62(14)$ & .07 \\
\hline Prior PCI, No. $(\%)$ & $173(12)$ & $122(12)$ & $51(11)$ & .84 \\
\hline Cardiac surgery, No. $(\%)^{*}$ & & & & $<.001$ \\
\hline Valvular $\dagger$ & $756(52)$ & $473(47)$ & $283(62)$ & \\
\hline CABG & $782(54)$ & $546(55)$ & $236(52)$ & \\
\hline Others & $235(16)$ & $159(16)$ & $76(17)$ & \\
\hline
\end{tabular}

PoAF, Postoperative atrial fibrillation; $S D$, standard deviation; $B M I$, body mass index; $I Q R$, interquartile range; $A f i b$, atrial fibrillation; $C O P D$, chronic obstructive pulmonary disease; $P C I$, percutaneous coronary intervention; $C A B G$, coronary artery bypass grafting. *Numbers for each type of cardiac surgery are not mutually exclusive, because some patients underwent multiple procedures. †Valvular surgery performed includes aortic $(69 \%)$, mitral $(26 \%)$, combination of aortic and mitral $(4.0 \%)$, and others $(1.2 \%)$.

when valvular surgery is combined with other types of surgery (Figure 1). In addition, there was a significantly higher risk with the use of cardiopulmonary bypass (OR, 2.4; 95\% CI, 1.7-3.5) compared with no bypass (Figure 2); use of cardioplegia (OR, 1.7; 95\% CI, 1.2-2.5) compared with no cardioplegia; and lower risk with off-pump CABG (OR, 0.62; 95\% CI, 0.41-0.96) compared with on-pump CABG.

When we explored interaction, we identified significant interaction between the use of pump (ie, off-pump vs onpump $\mathrm{CABG}$ ) and 2 of our prespecified variables, that is, sex $(P$ for interaction $=.04)$ and age $(P$ for interaction $=.04)$. Compared with on-pump CABG, offpump CABG was significantly associated with a lower risk of PoAF (OR, 0.53; 95\% CI, 0.33-0.85) among men, but there was no significant difference in this risk between on-pump and off-pump CABG among women (OR, 1.7; 95\% CI, 0.61-4.5). Likewise, compared with on-pump CABG, off-pump CABG was significantly associated with a lower risk of PoAF among patients aged less than 65 years (OR, 0.35; 95\% CI, 0.16-0.75), but there was no significant difference in this risk between on-pump and off-pump CABG among patients aged 65 years or more (OR, 0.88;
$95 \%$ CI, 0.52-1.5). None of the other interactions as prespecified were statistically significant.

When we combined surgery characteristics and other covariates that showed some univariate association (ie, $P<.2$ ) with PoAF in a prediction model, both the type of surgery and the use of cardiopulmonary bypass independently predicted the risk of PoAF (Table 3). However, off-pump versus on-pump CABG was not included in this model because it was essentially a distinction within a category of patients who underwent CABG (ie, 54\% of the total patient population). Other independent predictors of PoAF included age, baseline use of antiarrhythmic, and baseline left atrial diameter (Table 3). In comparison, use of cardioplegia was no longer independently associated with risk of PoAF. Similar predictors were identified for PoAF $\mathrm{FT}_{\mathrm{NT}}$ but with lower statistical power as expected (Table E3).

\section{Surgical and Patient Characteristics and Risk of Major Adverse Cardiovascular Event and Mortality}

The incidence of MACE increased from postoperative day 1 to a peak on day 3, and then was lower thereafter (Figure E2). Among surgery characteristics, only the 
TABLE 2. Surgery characteristics and incidence of postoperative atrial fibrillation among patients undergoing cardiac surgery in the OPERA trial

\begin{tabular}{|c|c|c|c|c|c|}
\hline \multirow[b]{2}{*}{ Surgery characteristics } & \multirow[b]{2}{*}{ No. of cases of PoAF/total N (\%) } & \multicolumn{2}{|c|}{ Univariate model } & \multicolumn{2}{|c|}{ Multivariable model ${ }^{*}$} \\
\hline & & OR $(95 \%$ CI $)$ & $P$ value & OR $(95 \%$ CI $)$ & $P$ value \\
\hline Overall & $460 / 1462(31)$ & & & & \\
\hline Type of surgery & & & & & $<.001 \dagger$ \\
\hline CABG & $155 / 601(26)$ & reference & & reference & \\
\hline Valvular & $163 / 479(34)$ & $1.5(1.1-1.9)$ & .003 & $1.4(1.1-1.9)$ & .01 \\
\hline $\mathrm{CABG}+$ valvular & $63 / 139(45)$ & $2.4(1.6-3.5)$ & $<.001$ & $1.8(1.2-2.7)$ & .005 \\
\hline CABG + valvular + & $11 / 23(48)$ & $2.6(1.1-6.1)$ & .02 & $2.9(1.2-7.2)$ & .01 \\
\hline \multicolumn{6}{|l|}{ Valve type } \\
\hline Mitral & $64 / 195(33)$ & reference & & reference & \\
\hline Aortic & $190 / 522(36)$ & $1.1(0.79-1.6)$ & .5 & $0.8(0.5-1.2)$ & .3 \\
\hline \multicolumn{6}{|l|}{ No. of bypass grafts } \\
\hline$<3$ & $93 / 289(32)$ & reference & & reference & \\
\hline 3 & $100 / 330(30)$ & $0.92(0.65-1.3)$ & .62 & $0.95(0.66-1.4)$ & .77 \\
\hline$>3$ & $45 / 168(27)$ & $0.77(0.51-1.2)$ & .23 & $0.80(0.51-1.3)$ & .33 \\
\hline \multicolumn{6}{|l|}{ Surgical approach } \\
\hline Full sternotomy & $437 / 1372(32)$ & reference & & reference & \\
\hline Minithoracotomy & $21 / 90(23)$ & $0.64(0.39-1.1)$ & .08 & $0.64(0.37-1.1)$ & .10 \\
\hline \multicolumn{6}{|l|}{ Cardiopulmonary bypass } \\
\hline No & $41 / 210(20)$ & reference & & reference & \\
\hline Yes & $417 / 1252(33)$ & $2.1(1.4-3.0)$ & $<.001$ & $2.4(1.7-3.5)$ & $<.001$ \\
\hline \multicolumn{6}{|l|}{ Use of pump $\ddagger$} \\
\hline On-pump CABG & $203 / 621(33)$ & reference & & reference & \\
\hline Off-pump CABG & $35 / 161(22)$ & $0.57(0.38-0.85)$ & .007 & $0.62(0.41-0.96)$ &. $\mathbf{0 3} \S$ \\
\hline Pump duration, $\min \|$ & 1242 - & $1.0(0.96-1.1)$ & .43 & $1.03(0.95-1.11)$ & .44 \\
\hline Cross duration, $\min \|$ & 1205 ฯ & $0.98(0.92-1.1)$ & .61 & $0.98(0.91-1.1)$ & .63 \\
\hline \multicolumn{6}{|l|}{ Use of cardioplegia } \\
\hline No & $45 / 219(21)$ & reference & & reference & \\
\hline Yes & $413 / 1243(33)$ & $1.9(1.4-2.7)$ & $<.001$ & $1.7(1.2-2.5)$ & .005 \\
\hline Cardioplegia dose, $\mathrm{mL} \#$ & 1248 ฯ & $1.06(1.02-1.1)$ & .004 & $1.09(1.04-1.13)$ & $<.001$ \\
\hline No. of cardioplegia dose & $1243 \pi$ & $1.01(0.99-1.03)$ & .16 & $1.03(1.01-1.05)$ & .01 \\
\hline \multicolumn{6}{|l|}{ Cardioplegia approach } \\
\hline Anterograde & $196 / 617(32)$ & reference & & reference & \\
\hline Retrograde & $29 / 88(33)$ & $1.1(0.66-1.7)$ & .81 & $1.1(0.66-1.8)$ & .87 \\
\hline Both & $188 / 538(35)$ & $1.2(0.91-1.5)$ & .24 & $1.3(0.99-1.7)$ & .06 \\
\hline \multicolumn{6}{|l|}{ Method of rhythm return } \\
\hline Spontaneous & $313 / 1024(31)$ & reference & & reference & \\
\hline Assisted** & $145 / 430(34)$ & $1.1(0.91-1.4)$ & .28 & $1.1(0.83-1.4)$ & .56 \\
\hline
\end{tabular}

Values in bold are statistically significant at $P<.05$. PoAF, Postoperative atrial fibrillation; $O R$, odds ratio; $C I$, confidence interval; $C A B G$, coronary artery bypass grafting; $C A B G+$ valvular, combination of $C A B G$ and valvular surgery; $C A B G+$ valvular + , surgeries involving CABG, valvular, and at least 1 other type of cardiac procedure. *Association between surgery characteristics and incidence of postoperative atrial fibrillation was assessed via multivariable logistic regression. Covariates were included via backward stepwise selection $(P$ exclusion $=.20, P$ inclusion $=.10)$, with forcing of age, sex, race, history of Afib, left atrial diameter, and COPD, and model-based selection of country BMI, hypertension, smoking, heart failure, renal failure, perioperative beta-blocker, statin and antiarrhythmic use, and prior PCI. $\nmid P$ trend $<.001$ across categories of surgery type as ordered in the Table (OR [95\% CI] for linear trend was 1.3 [1.1-1.4]). $\ddagger$ Use of pump (ie, off pump vs on-pump) is essentially a distinction within category of CABG alone. $\S$ There was significant interaction between use of pump (ie, off-pump vs on-pump CABG) and 2 of our prespecified variables-sex $(P$ for interaction $=.04)$ and age $(P$ for interaction $=.04)$. Compared with on-pump, off-pump was significantly associated with lower risk of POAF (OR, 0.53 [95\% CI, 0.33-0.85], $P=.008)$ among men, but there was no significant difference in this risk between on-pump and off-pump among women (OR, 1.7 [95\% CI, 0.61-4.5], $P=.32$ ). Also, compared with on-pump, off-pump was significantly associated with a lower risk of POAF among patients aged less than 65 years ( $\mathrm{OR}, 0.35$ [ $95 \% \mathrm{CI}, 0.16-0.75], P=.007)$, but there was no significant difference in this risk between on-pump and off-pump among patients aged 65 years or more (OR, 0.88 [95\% CI, $0.52-1.5], P=.63)$. $\|$ OR represents change in odds per 10-minute increase in duration. 9 Indicates the number of patients with nonmissing value for the variable. \#OR represents change in odds per every $500 \mathrm{~mL}$ increase in the dose of cardioplegia. $* * A s-$ sisted method of rhythm return includes defibrillation, atrial pacing, and ventricular pacing.

method of rhythm return was significantly associated with the risk of MACE (Table E4). Compared with the spontaneous method of rhythm return, the assisted method was associated with a higher risk of MACE (OR, $2.5 ; 95 \% \mathrm{CI}$, 1.2-5.0) (Figure 3), and among the 3 assisted methods of rhythm return, ventricular pacing was associated with the 


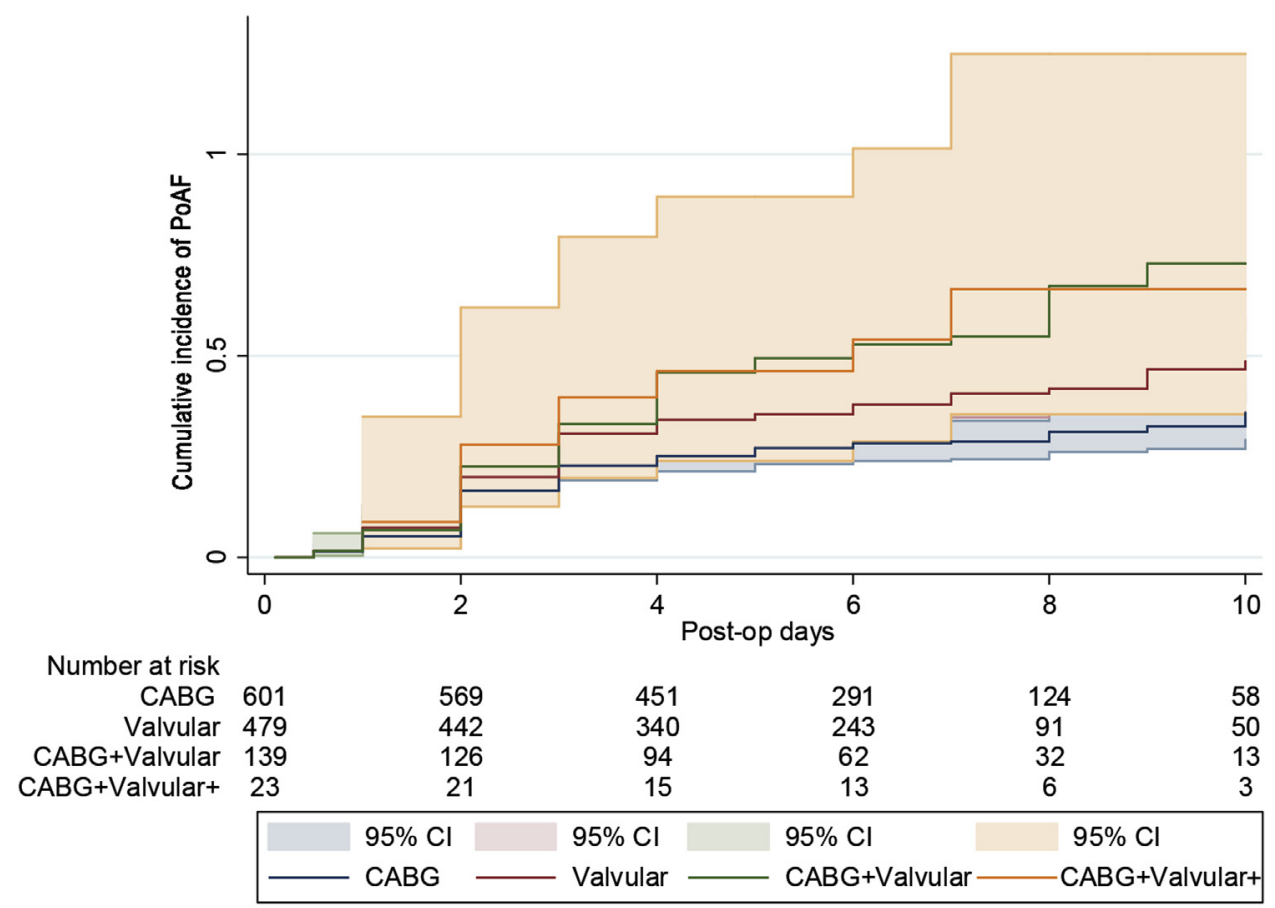

FIGURE 1. Cumulative incidence of postoperative atrial fibrillation among patients undergoing cardiac surgery, according to type of surgery. $P o A F$, Postoperative atrial fibrillation; $C A B G$, coronary artery bypass grafting; $C A B G+$ valvular, combination of $C A B G$ and valvular surgery; $C A B G+$ valvular + , surgeries involving $\mathrm{CABG}$, valvular, and at least 1 other type of cardiac procedure; $C I$, confidence interval.

highest risk of MACE (OR, 5.0; 95\% CI, 1.4-18) (Figure E3). None of the other surgery or patient characteristics independently predicted the risk of MACE.

When we evaluated the surgery characteristics and postoperative mortality, only the type of surgery was significantly associated with 30-day mortality (Figure 4). Compared with CABG alone, there was a nonsignificant higher risk of 30-day mortality with valvular surgery alone (hazard ratio [HR], 1.8; 95\% CI, 0.61-5.5). However, the risk became significantly higher with concomitant $\mathrm{CABG}$ and valvular surgery (HR, 4.3; 95\% CI, 1.2-14) compared with $\mathrm{CABG}$ alone. In addition, there was a significant trend across the 3 categories of surgery type ( $\mathrm{HR}_{\text {trend }}, 1.4 ; 95 \%$ CI, 1.0-2.0). Among patient characteristics, 30-day mortality was independently predicted by sex and marginally by perioperative statin use (Table 4), whereas 1-year mortality was predicted by age, sex, COPD, and perioperative statin use (Table 5).
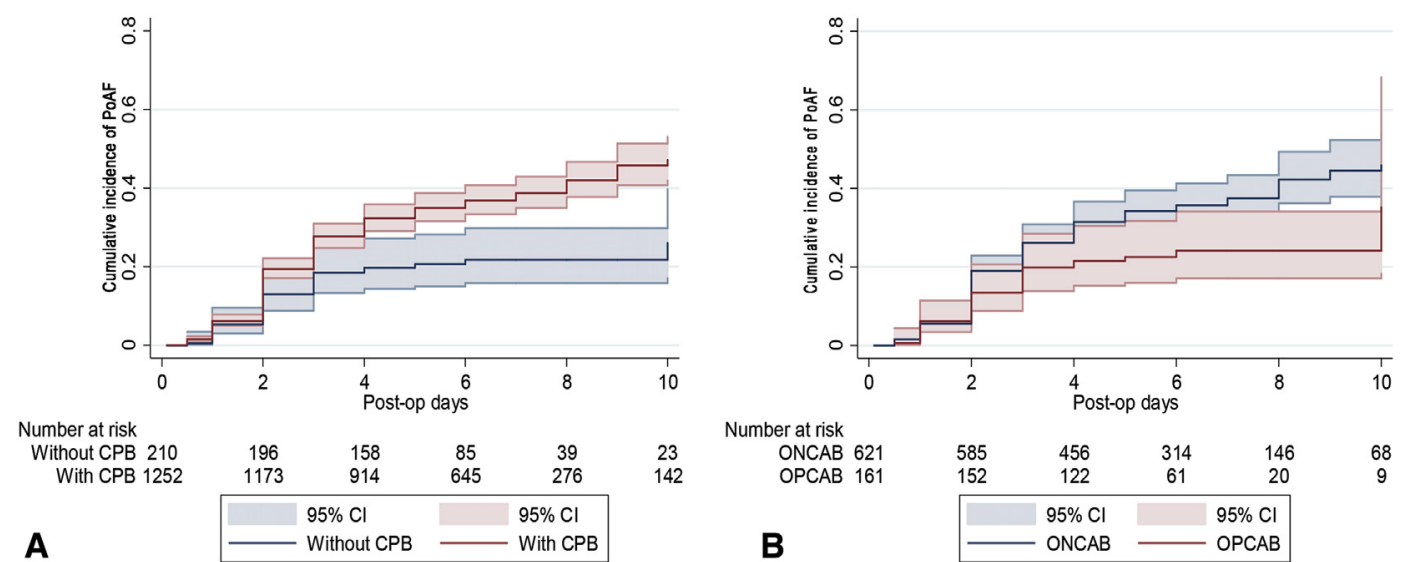

FIGURE 2. Cumulative incidence of PoAF among patients undergoing cardiac surgery, according to use of $\mathrm{CPB}$ ( $\mathrm{A}=$ among the entire patient population; $\mathrm{B}=$ among subgroup of patients who underwent $\mathrm{CABG}$ ). $P O A F$, Postoperative atrial fibrillation; $C P B$, cardiopulmonary bypass; $C I$, confidence interval; $O N C A B$, on-pump coronary artery bypass; $O P C A B$, off-pump coronary artery bypass. 
TABLE 3. Independent predictors of postoperative atrial fibrillation among patients undergoing cardiac surgery in the OPERA trial*

\begin{tabular}{|c|c|c|}
\hline Predictors & OR $(95 \%$ CI $)$ & $P$ value \\
\hline Age & $1.7(1.5-1.9) \dagger$ & $<.001$ \\
\hline Female & $0.77(0.59-1.02)$ & .06 \\
\hline Hypertension $\ddagger$ & $1.2(0.91-1.7)$ & .12 \\
\hline Renal failure $\ddagger$ & $0.96(0.88-1.1)$ & .43 \\
\hline Current smoking $\ddagger$ & $0.89(0.63-1.3)$ & .59 \\
\hline History of Afib & $1.0(0.99-1.0)$ & .90 \\
\hline COPD & $1.3(0.90-1.8)$ & .17 \\
\hline Perioperative beta-blocker & $0.81(0.62-1.1)$ & .07 \\
\hline Baseline use of antiarrhythmic & $1.7(1.1-2.9)$ & .03 \\
\hline Left atrial diameter & $1.4(1.2-1.7) \dagger$ & .001 \\
\hline $\begin{array}{l}\text { Type of surgery } \\
\text { CABG }\end{array}$ & reference & $.005 \S$ \\
\hline Valvular & $1.3(0.96-1.8)$ & .08 \\
\hline CABG + valvular & $1.7(1.1-2.5)$ & .01 \\
\hline CABG + valvular + & $2.4(1.0-5.8)$ & .05 \\
\hline \multicolumn{3}{|l|}{ Cardiopulmonary bypass } \\
\hline No & reference & \\
\hline Yes & $1.6(1.1-2.3)$ & .02 \\
\hline \multicolumn{3}{|l|}{ Use of cardioplegia } \\
\hline No & reference & \\
\hline Yes & $1.3(0.71-2.5)$ & $.38 \|$ \\
\hline
\end{tabular}

Values in bold are statistically significant at $P<.05 . O R$, Odds ratio; $C I$, confidence interval; $A f i b$, atrial fibrillation; $C O P D$, chronic obstructive pulmonary disease; $C A B G$, coronary artery bypass graft; $C A B G+$ valvular, combination of $\mathrm{CABG}$ and valvular surgery; $C A B G+$ valvular + , surgeries involving $C A B G$, valvular, and at least 1 other type of cardiac procedure. *Evaluation for independent predictors was assessed by including all these variables (with $P<.2$ in a univariate analysis with atrial fibrillation) in a single model. C-statistic for the multivariable model was 0.73. Subgroup variables in Table 2-valve type, number of bypass grafts, offpump versus on-pump CABG, pump duration, cross duration, cardioplegia dose, number of cardioplegia dose and cardioplegia approach — were not considered for inclusion in the predictive model because including them would restrict analysis to only patients within the subgroup. $\dagger \mathrm{OR}$ represents change in the odds per 10-unit increase in the variable. The unit of measurement was years for age and millimeters for left atrial diameter. $\downarrow$ †ypertension, renal failure, and current smoking became nonsignificant after adjusting for age. $\S P$ trend across the categories of surgery type as ordered in the Table (OR $[95 \% \mathrm{CI}]$ for linear trend was 1.2 [1.1-1.4]). \|Use of cardioplegia became nonsignificant after inclusion of cardiopulmonary bypass in the model.

\section{Impact of Postoperative Atrial Fibrillation}

In multivariable-adjusted models, occurrence of PoAF was associated with increased resource use, including length of ICU/CCU stay and total hospital stay (Table E5). On average, patient with PoAF spent $0.69(95 \% \mathrm{CI}$, 0.43-0.95) more days in the ICU/CCU and $1.3(95 \% \mathrm{CI}$, 0.71-1.9) more total hospital days than those without PoAF. Other predictors of resource use are available in Tables E6 and E7.

Occurrence of PoAF was significantly associated with 1year mortality (HR, 2.2; 95\% CI, 1.2-3.9) (Figure 5), whereas $\mathrm{PoAF}_{\mathrm{NT}}$ was significantly associated with both 30-day (HR, 3.1; 95\% CI, 1.2-7.8) and 1-year mortality (HR, 3.2; 95\% CI, 1.2-8.4) (Table E8).

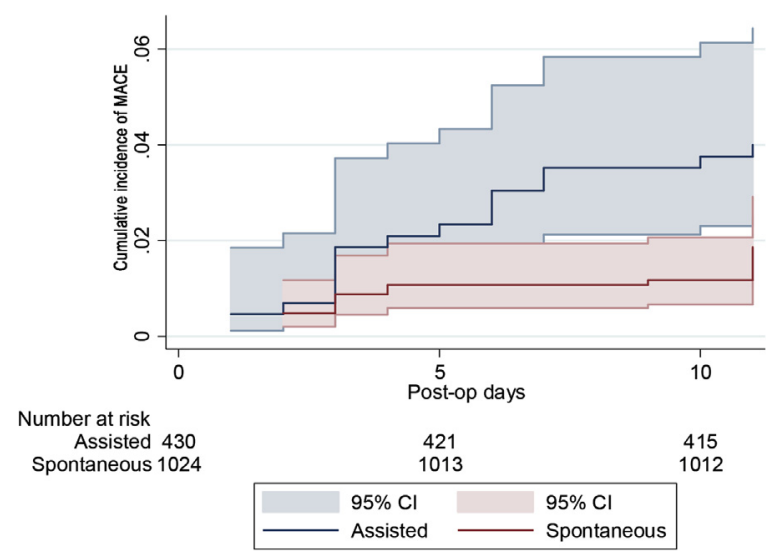

FIGURE 3. Cumulative incidence of in-hospital MACE among patients undergoing cardiac surgery, according to method of rhythm return. Assisted method of rhythm return includes atrial pacing, defibrillation, and ventricular pacing. MACE, Major adverse cardiovascular event; $C I$, confidence interval.

\section{DISCUSSION}

In this multicenter clinical trial of patients undergoing cardiac surgery in the United States, Italy, and Argentina, we identified specific surgery and patient characteristics that were associated with adverse outcomes of PoAF, MACE, and mortality. We found that the type of surgery and use of cardiopulmonary bypass (including off-pump [vs on-pump] CABG) were associated with PoAF. Among patient factors, age, baseline use of antiarrhythmic, and left atrial diameter independently predicted the risk of PoAF. When additional complications were evaluated, the method of rhythm return was associated with the risk of MACE, whereas the type of surgery was associated with 30-day mortality. Last, we showed that the occurrence of PoAF was associated with increased resource use as defined by ICU/CCU stay and total hospital stay, and mortality.

Our study builds on and considerably extends on findings from prior studies. The results are consistent with prior studies that have shown the incidence of PoAF after cardiac surgery was significantly higher with concomitant CABG and valve surgery, ${ }^{13,21}$ as well as with the use of cardiopulmonary bypass. ${ }^{22,23}$ Furthermore, our study provides novel evidence of a graded increase in the risk of PoAF across the 4 categories of cardiac surgeries as prespecified (ie, from CABG alone through combination of CABG, valvular surgery, and at least 1 other procedure). Although prior studies have suggested a higher risk of PoAF with valve surgery, as well as a combination of $\mathrm{CABG}$ and valvular surgery compared with CABG alone, ${ }^{6,24}$ we are not aware of any study to date to demonstrate this graded increase in the risk of PoAF in a multivariable analysis, thereby representing a novel evidence of the additive effect of the different type of cardiac surgery on the pathophysiology or myocardial 


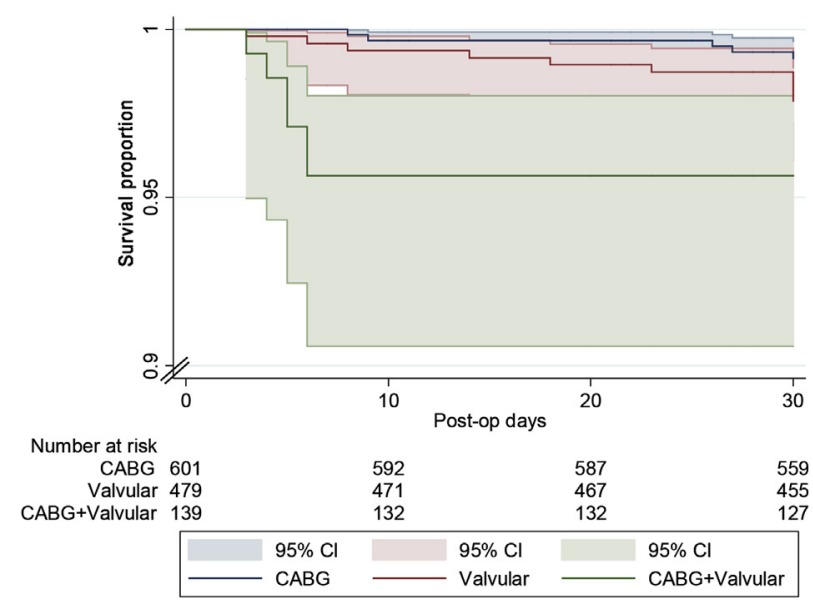

FIGURE 4. The 30-day Kaplan-Meier survival curve among patients undergoing cardiac surgery, according to type of surgery. $C A B G$, Coronary artery bypass grafting; $C A B G+$ valvular, combination of $C A B G$ and valvular surgery; $C I$, confidence interval.

remodeling underlying PoAF. By extending the results of prior studies, ${ }^{22,23}$ we also showed that among patients undergoing $\mathrm{CABG}$, the association of off-pump (vs onpump) CABG with the incidence of PoAF varies with gender and age. Specifically, the lower risk of PoAF with off-pump CABG was only significant in men (but nonsignificant in women), and this protective benefit was evident only among patients aged less than 65 years.

In addition, we provide initial empirical evidence that the method of rhythm return after cardiac surgery is associated with MACE. Specifically, the assisted method of rhythm return (especially ventricular pacing) is significantly associated with a higher risk of MACE. Lack of a coordinated atrial contraction with ventricular pacing has been implicated as a mechanistic link for poor hemodynamic parameters, including low cardiac output, ${ }^{25-27}$ and may underlie the high incidence of MACE after pacing. Although the results on the association between the type of surgery and the combination of surgery on the risk of 30-day mortality have been mixed in the literature, ${ }^{28-33}$ our study demonstrates that in a generalizable patient population, a combination of CABG with valvular surgery is associated with a higher risk of 30-day mortality compared with CABG alone.

Our study has important clinical implications. First, we identified high-risk surgery characteristics and practices that warrant consideration for prophylaxis for PoAF, MACE, and mortality. ${ }^{34}$ Although the protective benefits of beta-blockers on PoAF, as well as statins on MACE and 30-day mortality, did not reach statistical significance in our study, prior studies have suggested that these therapies may reduce the risk of these adverse outcomes. ${ }^{35-38}$ In addition, we showed in our study that perioperative statin use significantly lowers the risk of 1-year mortality.
TABLE 4. Independent predictors of 30-day mortality among patients undergoing cardiac surgery in the OPERA trial*

\begin{tabular}{lcc}
\hline \multicolumn{1}{c}{ Predictors } & HR $(\mathbf{9 5} \% \mathbf{C I})$ & $\boldsymbol{P}$ value \\
\hline Age & $1.5(0.94-2.4) \dagger$ & .08 \\
Female & $2.8(1.05-7.7)$ & $\mathbf{. 0 4}$ \\
Perioperative beta-blocker & $0.44(0.12-1.2)$ & .09 \\
Perioperative statin & $0.22(0.05-1.0)$ & .05 \\
Type of surgery & & $\mathbf{. 0 4} \ddagger$ \\
CABG & reference & \\
Valvular & $1.8(0.61-5.5)$ & .28 \\
CABG + valvular & $4.3(1.2-14)$ & $\mathbf{. 0 1}$ \\
CABG + valvular + & $\S$ & \\
\hline
\end{tabular}

Values in bold are statistically significant at $P<.05 . H R$, Hazard ratio; $C I$, confidence interval; $C A B G$, coronary artery bypass grafting; $C A B G+$ valvular, combination of CABG and valvular surgery; $C A B G+$ valvular + , surgeries involving $C A B G$, valvular, and at least 1 other type of cardiac procedure. *Evaluation for independen predictors was assessed by including all these variables (with $P<.2$ in a univariate analysis with atrial fibrillation) in a single model. C-statistic for the multivariable model was 0.75 . Subgroup variables in Table 2-valve type, number of bypass grafts off-pump versus on-pump CABG, pump duration, cross duration, cardioplegia dose, number of cardioplegia dose, and cardioplegia approach — were not considered for inclusion in the predictive model because including them would restrict analysis to only patients within the subgroup. $\dagger$ HR represents change in the odds per 10-year increase in age. $\ddagger P$ trend $=.04$ across the categories of surgery type as ordered in the Table (HR [95\% CI] for linear trend was 1.4 [1.0-2.0]). §HR not estimable because there was no case in the group.

These may be considered for high-risk surgeries, especially when these findings are confirmed in randomized trials. Second, because of the increasing trend in the rate of valvular surgery, as well as the combination of CABG and valvular surgery performed in the United States, ${ }^{39,40}$ our study highlights the need for new guidelines or update to current guidelines (that addressed only isolated CABG) to incorporate these relatively high-risk procedures that we identified to be associated with higher risk of PoAF or mortality compared with isolated CABG in the OPERA trial. ${ }^{41}$ In this generalizable patient population undergoing various surgical procedures, we highlighted key independent predictors (including patient and surgery characteristics) of PoAF and mortality that should be considered for risk stratification.

\section{Study Limitations}

Potential limitations of this study should be considered. First, the study has a nonrandomized observational design that precludes causal interpretation of the associations. For example, although some of the complications (eg, stroke) are causally related to PoAF, others, such as ICU length of stay, could be a correlate of poor postoperative course. However, given the nature of the research question, it will be impossible to have a randomized design for most of these surgery characteristics because they are selected only by patient-specific indications and postoperative course. We mitigated against possible bias of the associations of interest by adjusting for potential confounders in 
TABLE 5. Independent predictors of 1-year mortality among patients undergoing cardiac surgery in the OPERA trial*

\begin{tabular}{lcc}
\hline \multicolumn{1}{c}{ Predictors } & HR $(\mathbf{9 5} \% \mathbf{C I})$ & $\boldsymbol{P}$ value \\
\hline Age & $1.4(1.1-1.9) \dagger$ & $\mathbf{. 0 2}$ \\
Female & $2.04(1.09-3.8)$ & $\mathbf{. 0 3}$ \\
COPD & $3.2(1.6-6.5)$ & $<.001$ \\
Perioperative beta-blocker & $0.71(0.34-1.5)$ & .37 \\
Perioperative statin & $0.39(0.17-0.88)$ & $\mathbf{. 0 3}$ \\
Country & & $.05 \ddagger$ \\
$\quad$ Italy & reference & \\
United States & $1.0(0.46-2.3)$ & .94 \\
$\quad$ Argentina & $1.9(0.99-4.1)$ & .05 \\
Type of surgery & & $.10 \S$ \\
CABG & reference & \\
Valvular & $1.2(0.59-2.6)$ & .58 \\
CABG + valvular & $2.1(0.87-5.0)$ & .09 \\
CABG + valvular + & $\|$ & \\
\hline
\end{tabular}

Values in bold are statistically significant at $P<.05$. HR, Hazard ratio; $C I$, confidence interval; $C O P D$, chronic obstructive pulmonary disease; $C A B G$, coronary artery bypass grafting; $C A B G+$ valvular, combination of $\mathrm{CABG}$ and valvular surgery; $C A B G+$ valvular + , surgeries involving $\mathrm{CABG}$, valvular, and at least 1 other type of cardiac procedure. *Evaluation for independent predictors was assessed by including all these variables (with $P<.2$ in a univariate analysis with atrial fibrillation) in a single model. C-statistic for the multivariable model was 0.75. Subgroup variables in Table 2-valve type, number of bypass grafts, pump duration, cross duration, cardioplegia dose, number of cardioplegia dose, and cardioplegia approachwere not considered for inclusion in the predictive model because including them would restrict analysis to only patients within the subgroup. $†$ HR represents change

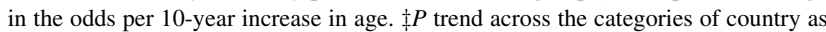
ordered in the Table. HR $(95 \% \mathrm{CI})$ for linear trend was $1.4(0.99-2.0)$. $\S P$ trend $=.10$ across the categories of surgery type as ordered in the table (HR $[95 \%$ CI] for linear trend was $1.3[0.95-1.7])$. |HR not estimable because there was no case in the group.

multivariable analysis. Second, this investigation was performed exclusively in patients undergoing cardiac surgery. Thus, our findings may not be extendable to other thoracic surgeries in which these end points are common.

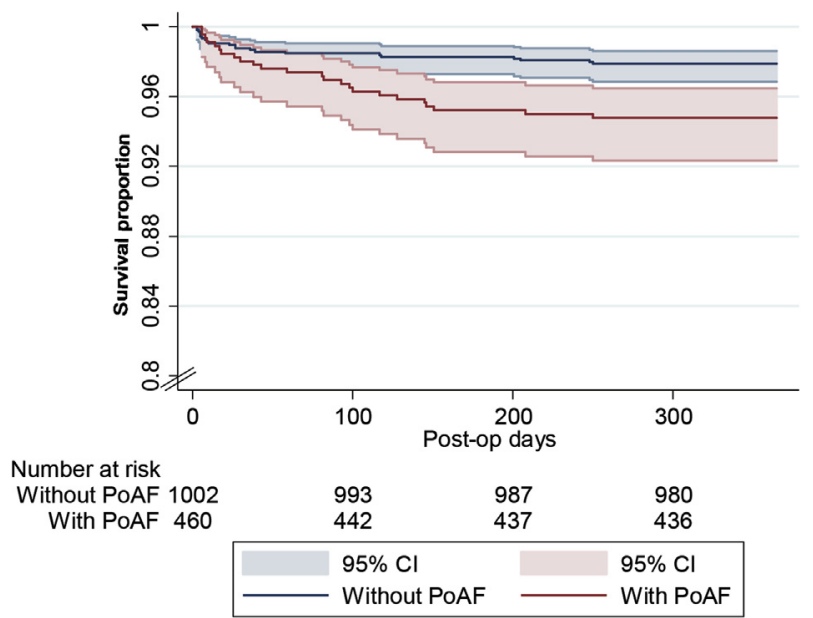

FIGURE 5. The 1-year Kaplan-Meier survival curve among patients undergoing cardiac surgery, according to incidence of postoperative atrial fibrillation. PoAF, Postoperative atrial fibrillation; $C I$, confidence interval.

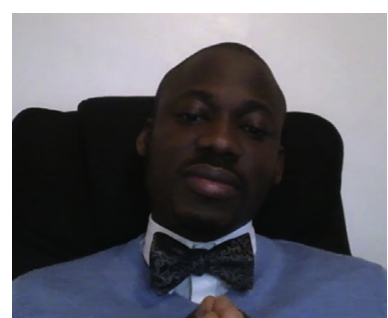

VIDEO 1. A video by the first author explaining the importance and main findings of the article. Video available at: http://www.jtcvsonline.org/ article/S0022-5223(17)31716-6/fulltext.

\section{CONCLUSIONS}

We identified surgery and patient characteristics that are associated with adverse clinical outcomes, especially postoperative atrial fibrillation (Video 1). We believe this relatively novel information will facilitate adequate patient education and counseling, inform guidelines for surgical practices, and identify procedures that will require perioperative prophylaxis.

\section{Conflict of Interest Statement}

D.M. reports ad hoc honoraria or consulting from Pollock Communications and chapter royalties from UpToDate. All other authors have nothing to disclose with regard to commercial support.

\section{References}

1. Hogue CW Jr, Creswell LL, Gutterman DD, Fleisher LA. Epidemiology, mechanisms, and risks: American College of Chest Physicians guidelines for the prevention and management of postoperative atrial fibrillation after cardiac surgery. Chest. 2005;128:9S-16S.

2. Mitchell LB. Canadian Cardiovascular Society Atrial Fibrillation Guidelines 2010: prevention and treatment of atrial fibrillation following cardiac surgery. Can J Cardiol. 2011;27:91-7.

3. Lahey SJ, Campos CT, Jennings B, Pawlow P, Stokes T, Levitsky S. Hospital readmission after cardiac surgery. Does "fast track" cardiac surgery result in cost saving or cost shifting? Circulation. 1998;98:II35-40.

4. Goldberger JJ, Arora R, Green D, Greenland P, Lee DC, Lloyd-Jones DM, et al. Evaluating the atrial myopathy underlying atrial fibrillation: identifying the arrhythmogenic and thrombogenic substrate. Circulation. 2015;132:278-91.

5. Ishii Y, Schuessler RB, Gaynor SL, Hames K, Damiano RJ Jr. Postoperative atrial fibrillation: the role of the inflammatory response. J Thorac Cardiovasc Surg. 2017; 153:1357-65.

6. Echahidi N, Pibarot P, O'Hara G, Mathieu P. Mechanisms, prevention, and treatment of atrial fibrillation after cardiac surgery. J Am Coll Cardiol. 2008;51: 793-801.

7. Zaman AG, Archbold RA, Helft G, Paul EA, Curzen NP, Mills PG. Atrial fibrillation after coronary artery bypass surgery: a model for preoperative risk stratification. Circulation. 2000;101:1403-8.

8. Almassi GH, Schowalter T, Nicolosi AC, Aggarwal A, Moritz TE, Henderson WG, et al. Atrial fibrillation after cardiac surgery: a major morbid event? Ann Surg. 1997;226:501-13.

9. Helgadottir S, Sigurdsson MI, Ingvarsdottir IL, Arnar DO, Gudbjartsson T. Atrial fibrillation following cardiac surgery: risk analysis and long-term survival. J Cardiothorac Surg. 2012;7:87.

10. Aranki SF, Shaw DP, Adams DH, Rizzo RJ, Couper GS, VanderVliet M, et al. Predictors of atrial fibrillation after coronary artery surgery. Current trends and impact on hospital resources. Circulation. 1996;94:390-7.

11. Rader F, Van Wagoner DR, Ellinor PT, Gillinov AM, Chung MK, Costantini O, et al. Influence of race on atrial fibrillation after cardiac surgery. Circ Arrhythm Electrophysiol. 2011;4:644-52. 
12. Mathew JP, Parks R, Savino JS, Friedman AS, Koch C, Mangano DT, et al. Atrial fibrillation following coronary artery bypass graft surgery: predictors, outcomes, and resource utilization. Multicenter study of perioperative ischemia research group. JAMA. 1996;276:300-6.

13. Mathew JP, Fontes ML, Tudor IC, Ramsay J, Duke P, Mazer CD, et al. A multicenter risk index for atrial fibrillation after cardiac surgery. JAMA. 2004;291: 1720-9.

14. Lamy A, Devereaux PJ, Prabhakaran D, Taggart DP, Hu S, Paolasso E, et al. Offpump or on-pump coronary-artery bypass grafting at 30 days. $N$ Engl J Med. 2012:366:1489-97.

15. Auer J, Weber T, Berent R, Ng CK, Lamm G, Eber B. Risk factors of postoperative atrial fibrillation after cardiac surgery. J Card Surg. 2005;20:425-31.

16. Kolek MJ, Muehlschlegel JD, Bush WS, Parvez B, Murray KT, Stein CM, et al. Genetic and clinical risk prediction model for postoperative atrial fibrillation. Circ Arrhythm Electrophysiol. 2015;8:25-31.

17. Mariscalco G, Biancari F, Zanobini M, Cottini M, Piffaretti G, Saccocci M, et al. Bedside tool for predicting the risk of postoperative atrial fibrillation after cardiac surgery: the POAF score. J Am Heart Assoc. 2014;3:e000752.

18. Mozaffarian D, Marchioli R, Macchia A, Silletta MG, Ferrazzi P, Gardner TJ, et al. Fish oil and postoperative atrial fibrillation: the Omega-3 Fatty Acids for Prevention of Post-operative Atrial Fibrillation (OPERA) randomized trial. JAMA. 2012;308:2001-11.

19. Mozaffarian D, Marchioli R, Gardner T, Ferrazzi P, O'Gara P, Latini R, et al. The omega-3 fatty acids for prevention of post-operative atrial fibrillation trial-rationale and design. Am Heart J. 2011;162:56-63.e53.

20. Azur MJ, Stuart EA, Frangakis C, Leaf PJ. Multiple imputation by chained equations: what is it and how does it work? Int J Methods Psychiatr Res. 2011;20: 40-9.

21. Rho RW. The management of atrial fibrillation after cardiac surgery. Heart. 2009; 95:422-9.

22. Angelini GD, Taylor FC, Reeves BC, Ascione R. Early and midterm outcome after off-pump and on-pump surgery in Beating Heart Against Cardioplegic Arrest Studies (BHACAS 1 and 2): a pooled analysis of two randomised controlled trials. Lancet. 2002;359:1194-9.

23. Wijeysundera DN, Beattie WS, Djaiani G, Rao V, Borger MA, Karkouti K, et al. Off-pump coronary artery surgery for reducing mortality and morbidity: metaanalysis of randomized and observational studies. J Am Coll Cardiol. 2005;46: 872-82.

24. Creswell LL, Schuessler RB, Rosenbloom M, Cox JL. Hazards of postoperative atrial arrhythmias. Ann Thorac Surg. 1993;56:539-49.

25. Curtis J, Walls J, Boley T, Reid J, Flaker G, Madigan N, et al. Influence of atrioventricular synchrony on hemodynamics in patients with normal and low ejection fractions following open heart surgery. Am Surg. 1986;52:93-6.

26. Curtis JJ, Maloney JD, Barnhorst DA, Pluth JR, Hartzler GO, Wallace RB. A critical look at temporary ventricular pacing following cardiac surgery. Surgery. 1977;82:888-93.

27. Reade MC. Temporary epicardial pacing after cardiac surgery: a practical review: Part 1: General considerations in the management of epicardial pacing. Anaesthesia. 2007;62:264-71.
28. Alexander KP, Anstrom KJ, Muhlbaier LH, Grosswald RD, Smith PK, Jones RH et al. Outcomes of cardiac surgery in patients $>$ or $=80$ years: results from the national cardiovascular network. J Am Coll Cardiol. 2000;35:731-8.

29. Beach JM, Mihaljevic T, Svensson LG, Rajeswaran J, Marwick T, Griffin B, et al Coronary artery disease and outcomes of aortic valve replacement for severe aortic stenosis. J Am Coll Cardiol. 2013;61:837-48.

30. Edwards FH, Peterson ED, Coombs LP, DeLong ER, Jamieson WR, Shroyer ALW, et al. Prediction of operative mortality after valve replacement surgery. J Am Coll Cardiol. 2001;37:885-92.

31. Freeman WK, Schaff HV, O’Brien PC, Orszulak TA, Naessens JM, Tajik AJ. Cardiac surgery in the octogenarian: perioperative outcome and clinical follow-up. $J$ Am Coll Cardiol. 1991;18:29-35.

32. Herlitz J, Brandrup-Wognsen G, Caidahl K, Haglid M, Karlsson BW, Karlsson T, et al. Mortality and morbidity among patients who undergo combined valve and coronary artery bypass surgery: early and late results. Eur J Cardiothorac Surg. 1997; 12:836-46

33. Teng Z, Ma X, Zhang Q, Yun Y, Ma C, Hu S, et al. Additional mitral valve procedure and coronary artery bypass grafting versus isolated coronary artery bypass grafting in the management of significant functional ischemic mitral regurgitation: a meta-analysis. J Cardiovasc Surg (Torino). 2017;58:121-30.

34. Amar D. Postoperative atrial fibrillation: is there a need for prevention? J Cardiovasc Surg. 2016;151:913-5.

35. Liakopoulos OJ, Choi YH, Haldenwang PL, Strauch J, Wittwer T, Dorge H, et al Impact of preoperative statin therapy on adverse postoperative outcomes in patients undergoing cardiac surgery: a meta-analysis of over 30,000 patients. Eur Heart J. 2008;29:1548-59.

36. Burgess DC, Kilborn MJ, Keech AC. Interventions for prevention of postoperative atrial fibrillation and its complications after cardiac surgery: a metaanalysis. Eur Heart J. 2006;27:2846-57.

37. Ozaydin M, Icli A, Yucel H, Akcay S, Peker O, Erdogan D, et al. Metoprolol vs. carvedilol or carvedilol plus n-acetyl cysteine on post-operative atrial fibrillation: a randomized, double-blind, placebo-controlled study. Eur Heart J. 2013;34:597-604.

38. Fedoruk LM, Wang H, Conaway MR, Kron IL, Johnston KC. Statin therapy improves outcomes after valvular heart surgery. Ann Thorac Surg. 2008;85:1521-6.

39. Shahian DM, O'Brien SM, Filardo G, Ferraris VA, Haan CK, Rich JB, et al. The Society of Thoracic Surgeons 2008 cardiac surgery risk models: Part 3-valve plus coronary artery bypass grafting surgery. Ann Thorac Surg. 2009;88:S43-62.

40. Goel K, Pack QR, Lahr B, Greason KL, Lopez-Jimenez F, Squires RW, et al. Cardiac rehabilitation is associated with reduced long-term mortality in patients undergoing combined heart valve and CABG surgery. Eur J Prev Cardiol. 2015;22: 159-68.

41. Hillis LD, Smith PK, Anderson JL, Bittl JA, Bridges CR, Byrne JG, et al. 2011 ACCF/AHA guideline for coronary artery bypass graft surgery: a report of the American College of Cardiology Foundation/American Heart Association Task Force on Practice Guidelines. Circulation. 2011;124:e652-735.

Key Words: adverse cardiovascular event, atrial fibrillation, cardiac surgery, mortality 


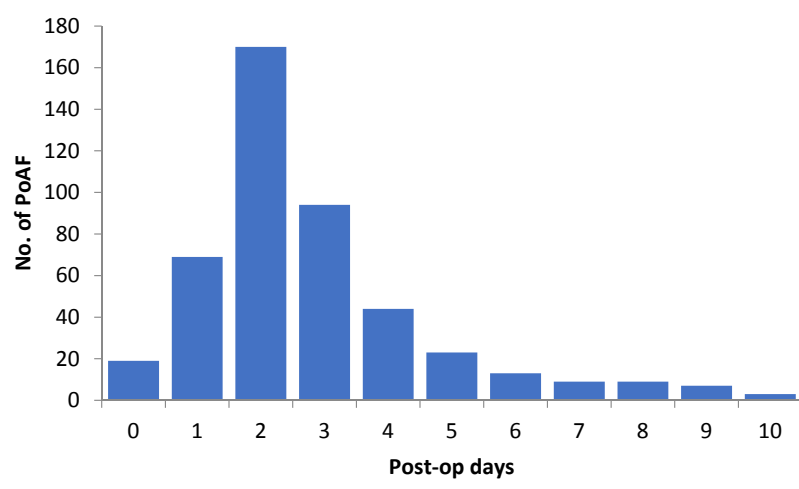

FIGURE E1. Absolute incidence of PoAF among 1462 patients undergoing cardiac surgery in the OPERA trial. PoAF, Postoperative atrial fibrillation.

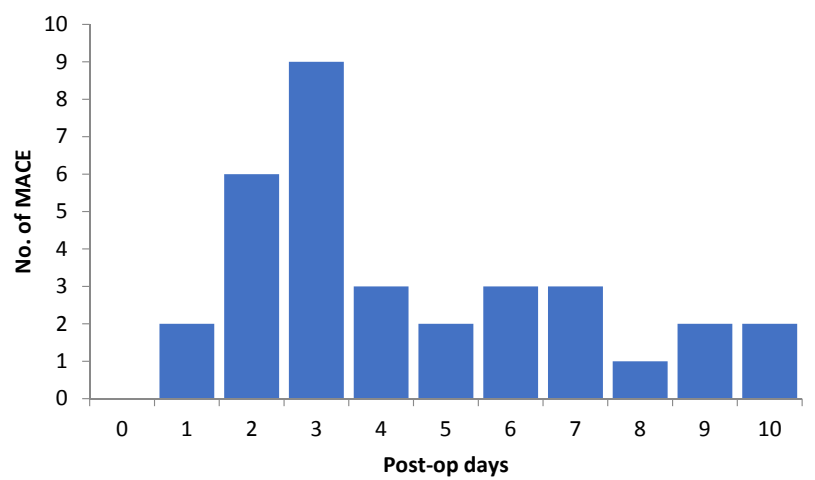

FIGURE E2. Absolute incidence of in-hospital MACE among 1462 patients undergoing cardiac surgery in the OPERA trial. MACE, Major adverse cardiovascular event. 


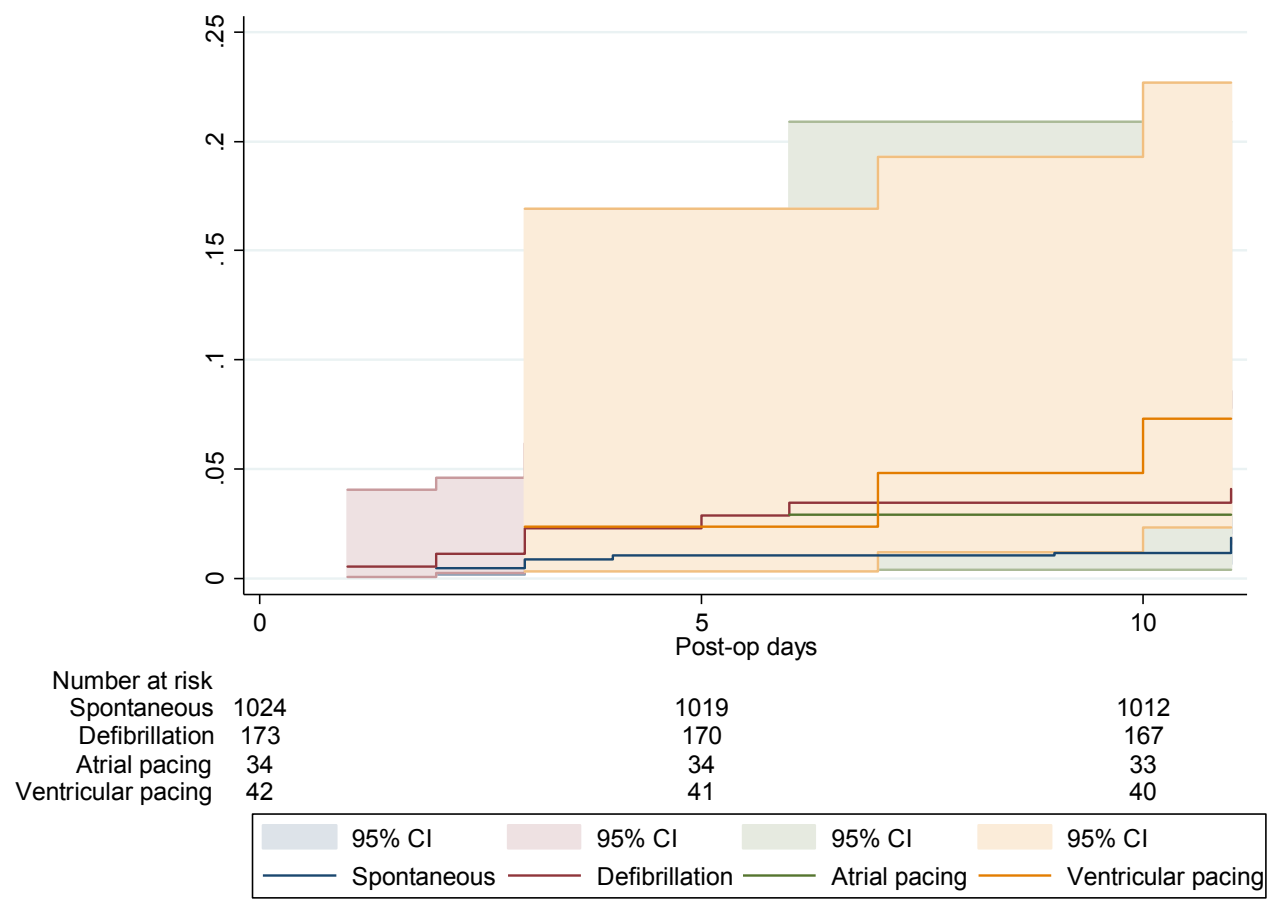

FIGURE E3. Cumulative incidence of in-hospital MACE among patients undergoing cardiac surgery, according to method of rhythm return. CI, Confidence interval. 
TABLE E1. Definition of end points

\begin{tabular}{|c|c|}
\hline End points & Definition \\
\hline AF or flutter* & $\begin{array}{l}\text { Any documented AF or AFL of at least } 30 \text {-s duration and documented by rhythm strip or 12-lead ECG. } \\
\text { AF, irregular ventricular response independent of rate, with the following characteristics: } \\
\text { - QRS complex unchanged from baseline or functional bundle branch block, and } \\
\text { - absence of P waves, or } \\
\text { - presence of fibrillary waves in isoelectric periods of the ECG. } \\
\text { AFL, with variable block, } 2: 1,3: 1 \text {, or } 4: 1 \text {, but not sinus tachycardia, with the following characteristics: } \\
\text { - QRS unchanged from baseline or functional bundle branch block, and } \\
\text { - absence of sinus P waves, and } \\
\text { - presence of flutter waves in isoelectric periods of the QRS complex of the ECG. }\end{array}$ \\
\hline $\mathrm{MACE} \dagger$ & $\begin{array}{l}\text { A composite of myocardial infarction, stroke, and cardiovascular death } \\
\text { - Myocardial infarction: } \\
\text { Within } 48 \mathrm{~h} \text { of surgery: new elevation of cardiac biomarkers at least } 5 \times \text { greater than the } 99 \% \text { upper range of } \\
\text { normal, together with at least } 1 \text { of the following: } 1 \text { ) new pathologic } \mathrm{Q} \text { waves or new LBBB, 2) } \\
\text { angiographically documented new graft or native coronary artery occlusion, or } 3 \text { ) imaging evidence of new } \\
\text { loss of viable myocardium. } \\
48 \text { h or more after surgery: increase or decrease of cardiac biomarkers (preferably troponin) with at least } 1 \\
\text { value }>99 \% \text { upper range of normal, together with evidence of myocardial ischemia with at least } 1 \text { of the } \\
\text { following: } 1 \text { ) symptoms of ischemia, } 2 \text { ) ECG changes indicative of new ischemia (see below), } 3 \text { ) } \\
\text { development of pathologic Q waves in the ECG, or } 4 \text { ) imaging evidence of new loss of viable myocardium } \\
\text { or new regional wall motion abnormality. [ECG changes: ST elevation }=\text { new ST elevation at the J point in } 2 \\
\text { contiguous leads, } \geq 0.2 \mathrm{mV} \text { in men or } \geq 0.15 \mathrm{mV} \text { in women in leads V2-V3, or } \geq 0.1 \mathrm{mV} \text { in other leads. ST } \\
\text { depression and T-wave changes }=\text { new horizontal or downsloping ST depression } \geq 0.05 \mathrm{mV} \text { in } 2 \text { contiguous } \\
\text { leads; or T inversion } \geq 0.1 \mathrm{mV} \text { in } 2 \text { contiguous leads with prominent R-wave or R/S ratio }>1 \text { ] } \\
\text { - Stroke: Acute neurologic deficit of vascular origin with symptoms or signs lasting more than } 24 \mathrm{~h} \text {. Subarachnoid } \\
\text { hemorrhage may not have focal deficit. From clinical symptoms, CT scan, or MRI report, stroke will be } \\
\text { classified as definite or probable ischemic stroke, definite hemorrhagic stroke, subarachnoid stroke, or uncertain } \\
\text { type of stroke. Hemorrhagic stroke does not include hemorrhage secondary to cerebral infarct, into a tumor, into } \\
\text { a vascular malformation, or post-traumatic hemorrhage } \\
\text { Cardiovascular death: Cardiac arrhythmic, cardiac nonarrhythmic, or vascular death }\end{array}$ \\
\hline Arterial thromboembolism $\dagger$ & $\begin{array}{l}\text { Inclusively defined to include any peripheral or systemic arterial thrombosis, transient ischemic attack, ischemic } \\
\text { stroke, or unknown stroke types (that would predominantly be ischemic). }\end{array}$ \\
\hline \multirow[t]{2}{*}{ Mortality } & 30-d mortality \\
\hline & 1-y mortality \\
\hline \multirow[t]{2}{*}{ Resource use $\S$} & Total ICU/CCU length of stay \\
\hline & $\begin{array}{l}\text { Total hospital length-of-stay, until death or discharge to home or to a rehabilitation or nursing unit or similar } \\
\text { facility }\end{array}$ \\
\hline \multicolumn{2}{|c|}{$\begin{array}{l}A F \text {, Atrial fibrillation; } A F L \text {, atrial flutter; } E C G \text {, electrocardiogram; } M A C E \text {, major adverse coronary events; } L B B B \text {, left bundle branch block; } C T \text {, computed tomography; } M R I \text {, } \\
\text { magnetic resonance imaging; } I C U \text {, intensive care unit; } C C U \text {, coronary care unit. *All potential episodes of AF or AFL were reviewed and adjudicated by the centralized events } \\
\text { committee, composed of cardiac electrophysiologists blinded to patient treatment assignment, using prespecified algorithms that make use of clinical information and direct re- } \\
\text { view of rhythm strips/12-lead ECGs. The time period of follow-up was from the time of cardiac surgery to hospital discharge or postoperative day } 10 \text {, whichever occurred first. } \\
\dagger \text { Assessed by centers on the basis of standardized algorithms and data-collection forms including detailed clinical event forms or adverse event reports and coding, with review } \\
\text { and over-reading by the Data Coordinating Center. In-hospital MACE was assessed from the time of enrollment to hospital discharge or postoperative day } 10 \text {, whichever occurred } \\
\text { first. Arterial thromboembolism was assessed from the time of enrollment to a minimum of } 2 \text { weeks after the last date of administration of study drug in the OPERA trial. } \ddagger \text { Thirty- } \\
\text { day mortality was assessed by center-based clinic or telephone follow-up, with all deaths reviewed and cause-specific deaths adjudicated by the Events Committee using stan- } \\
\text { dardized definitions, available from the authors on request. The time period of follow-up was from enrollment to } 30 \text { days after cardiac surgery. One-year all-cause mortality was } \\
\text { assessed by center-based clinic or telephone follow-up, with the time period of follow from enrollment to approximately } 1 \text { year. } \S U s e \text { end points were based on the total in-hospital } \\
\text { days for each patient (ie, including initial days and subsequent days if patients returned to this level of treatment), without adjustment for partial days. }\end{array}$} \\
\hline
\end{tabular}


TABLE E2. Cardiac surgery characteristics and postoperative medications of the OPERA participants

\begin{tabular}{lc}
\multicolumn{1}{c}{ Variables } & Total $(\mathbf{n}=\mathbf{1 4 6 2})$ \\
\hline Cardiac surgery characteristics & \\
Valve surgery, $\mathrm{n}(\%)$ & $756(52)$ \\
Type of valve, $\mathrm{n}(\%)$ & \\
Aortic & $522(69)$ \\
Mitral & $195(26)$ \\
Aortic + mitral & $30(4)$ \\
Other & $9(1.2)$ \\
CABG, $\mathrm{n}(\%)$ & $782(53)$ \\
Bypass grafts, no. (SD) & $2.8(1.1)$ \\
AF ablation performed, n (\%) & $15(1.0)$ \\
CPB, $\mathrm{n}(\%)$ & $1252(86)$ \\
Off pump, $\mathrm{n}(\%)$ & $174(12)$ \\
Mini-thoracotomy, $\mathrm{n}(\%)$ & $90(6.0)$ \\
Duration of pump time, $\mathrm{h}(\mathrm{SD})$ & $1.7(1.0)$ \\
Duration of crossclamp time, $\mathrm{h}(\mathrm{SD})$ & $1.2(0.79)$ \\
Cardioplegia, $\mathrm{n}(\%)$ & $1243(85)$ \\
Postoperative medications* & \\
Beta-blocker, $\mathrm{n}(\%)$ & $1033(71)$ \\
Calcium channel blocker, $\mathrm{n}(\%)$ & $131(9.0)$ \\
Angiotensin-converting enzyme inhibitor, $\mathrm{n}(\%)$ & $538(37)$ \\
Angiotensin receptor blocker, $\mathrm{n}(\%)$ & $209(14)$ \\
Statin, $\mathrm{n}(\%)$ & $835(57)$ \\
Digitalis, $\mathrm{n}(\%)$ & $16(1.1)$ \\
Antiarrhythmic & \\
Amiodarone, $\mathrm{n}(\%)$ & $398(27)$ \\
Flecainide, $\mathrm{n}(\%)$ & $6(0.41)$ \\
Propafenone, $\mathrm{n}(\%)$ & $2(0.14)$ \\
Disopyramide, $\mathrm{n}(\%)$ & $6(0.61)$ \\
Sotalol, $\mathrm{n}(\%)$ & $9(0.61)$ \\
\hline
\end{tabular}

Values are mean (SD) for continuous variables and number (\%) for categoric variables. $C A B G$, Coronary artery bypass grafting; $S D$, standard deviation; $A F$, atrial fibrillation; $C P B$, cardiopulmonary bypass. *Used on any postoperative days. 
TABLE E3. Independent predictors of new-onset postoperative atrial fibrillation requiring treatment among patients undergoing cardiac surgery in the OPERA trial*

\begin{tabular}{|c|c|c|}
\hline Predictors & OR $(95 \%$ CI $)$ & $P$ value \\
\hline Age & $1.6(1.4-1.8) \dagger$ & $<.001$ \\
\hline Female & $0.77(0.56-1.0)$ & .08 \\
\hline Hypertension $\ddagger$ & $0.99(0.97-1.0)$ & .45 \\
\hline Renal failure $\ddagger$ & $0.97(0.88-1.1)$ & .54 \\
\hline Current smoking $\ddagger$ & $0.93(0.60-1.4)$ & .73 \\
\hline History of Afib & $0.99(0.97-1.0)$ & .10 \\
\hline COPD & $1.0(0.69-1.6)$ & .87 \\
\hline Perioperative beta-blocker & $0.96(0.73-1.3)$ & .80 \\
\hline Baseline use of antiarrhythmic & $1.6(0.72-3.7)$ & .25 \\
\hline Left atrial diameter & $1.2(1.0-1.5) \dagger$ & .04 \\
\hline Type of surgery & & $.01 \S$ \\
\hline CABG & reference & \\
\hline Valvular & $1.3(0.89-1.8)$ & .19 \\
\hline CABG + valvular & $1.7(1.1-2.8)$ & .01 \\
\hline $\mathrm{CABG}+$ valvular + & $1.9(0.96-4.5)$ & .09 \\
\hline \multicolumn{3}{|l|}{ Cardiopulmonary bypass } \\
\hline No & reference & \\
\hline Yes & $2.3(0.99-5.4)$ & .05 \\
\hline \multicolumn{3}{|l|}{ Use of cardioplegia } \\
\hline No & reference & \\
\hline Yes & $0.57(0.25-1.3)$ & .18 \\
\hline
\end{tabular}

Values in bold are statistically significant at $P<.05$. OR, Odds ratio; $C I$, confidence interval; $A f i b$, atrial fibrillation; $C O P D$, chronic obstructive pulmonary disease; $C A B G$, coronary artery bypass graft; $C A B G+$ valvular, combination of $C A B G$ and valvular surgery; $C A B G+$ valvular + , surgeries involving $C A B G$, valvular, and at least 1 other type of cardiac procedure. *Evaluation for independent predictors was assessed by including all these variables (with $P<.2$ in a univariate analysis with atrial fibrillation) in a single model. Subgroup variables in Table 2—valve type, number of bypass grafts, off-pump versus on-pump CABG, pump duration, cross duration, cardioplegia dose, number of cardioplegia dose, and cardioplegia approach-were not considered for inclusion in the predictive model because including them would restrict analysis to only patients within the subgroup. $\nmid \mathrm{OR}$ represents change in the odds per 10-unit increase in the variable. The unit of measurement was years for age and millimeters for left atrial diameter. $\ddagger$ Hypertension, renal failure, and current smoking became nonsignificant after adjusting for age. $\S P$ trend across the categories of surgery type as ordered in the table $(\mathrm{OR}[95 \% \mathrm{CI}]$ for linear trend was $1.2[1.0-$ $1.3])$. 
TABLE E4. Surgery characteristics and incidence of in-hospital major cardiovascular disease event among patients undergoing cardiac surgery in the OPERA trial

\begin{tabular}{|c|c|c|c|c|c|}
\hline \multirow[b]{2}{*}{ Surgery characteristics } & \multirow[b]{2}{*}{ No of cases of PoAF/Total N } & \multicolumn{2}{|c|}{ Univariate model } & \multicolumn{2}{|c|}{ Multivariable model* } \\
\hline & & $\overline{\text { OR }(95 \% \text { CI })}$ & $P$ value & $\overline{\text { OR }(95 \% ~ C I)}$ & $P$ value \\
\hline Type of surgery & & & & & $.83 \dagger$ \\
\hline CABG & $14 / 601$ & reference & & reference & \\
\hline Valvular & $7 / 479$ & $0.62(0.25-1.5)$ & .66 & $0.54(0.25-1.4)$ & .20 \\
\hline $\mathrm{CABG}+$ valvular & $3 / 139$ & $0.92(0.26-3.2)$ & .82 & $0.85(0.19-2.5)$ & .81 \\
\hline $\mathrm{CABG}+$ valvular + & $1 / 23$ & $1.8(0.22-14)$ & .59 & $1.7(0.21-13)$ & .59 \\
\hline \multicolumn{6}{|l|}{ Valve type } \\
\hline Mitral & $2 / 184$ & reference & & reference & \\
\hline Aortic & $11 / 504$ & $2.0(0.45-9.2)$ & .36 & $2.4(0.50-11)$ & .28 \\
\hline \multicolumn{6}{|l|}{ No. of bypass grafts } \\
\hline$<3$ & $9 / 288$ & reference & & reference & \\
\hline 3 & $7 / 326$ & $0.67(0.29-2.0)$ & .60 & $0.81(0.29-2.1)$ & .68 \\
\hline$>3$ & $4 / 168$ & $0.76(0.23-2.5)$ & .65 & $0.88(0.26-3.0)$ & .84 \\
\hline \multicolumn{6}{|l|}{ Surgical approach } \\
\hline Full sternotomy & $29 / 1372$ & reference & & reference & \\
\hline Minithoracotomy & $2 / 90$ & $1.0(0.24-4.5)$ & .62 & $0.99(0.23-4.0)$ & .98 \\
\hline \multicolumn{6}{|l|}{ Cardiopulmonary bypass } \\
\hline No & $2 / 210$ & reference & & reference & \\
\hline Yes & $29 / 1252$ & $2.5(0.59-10)$ & .22 & $2.3(0.54-9.7)$ & .26 \\
\hline \multicolumn{6}{|l|}{ Use of pump $\ddagger$} \\
\hline On-pump & $21 / 621$ & reference & & reference & \\
\hline Off-pump & $0 / 161 \S$ & - & & - & \\
\hline Pump duration, $\min \|$ & $1242 ף$ & $1.1(0.86-1.3)$ & .54 & $1.1(0.86-1.3)$ & .54 \\
\hline Cross duration, $\min \|$ & 12059 & $1.1(0.86-1.3)$ & .62 & $1.1(0.87-1.3)$ & .56 \\
\hline \multicolumn{6}{|l|}{ Cardioplegia } \\
\hline No & $1 / 220$ & reference & & reference & \\
\hline Yes & $30 / 1244$ & $5.4(0.73-40)$ & .09 & $5.0(0.68-37)$ & .11 \\
\hline \multicolumn{6}{|l|}{ Assisted rhythm return } \\
\hline No & $15 / 1024$ & reference & & reference & \\
\hline Yes & $16 / 430$ & $2.6(0.01-5.3)$ & .009 & $2.5(1.2-5.0)$ & .01 \\
\hline Rhythm return method & & & & & $.02 \#$ \\
\hline Spontaneous & $15 / 1024$ & reference & & reference & \\
\hline Atrial pacing & $1 / 34$ & $2.0(0.26-16)$ & .50 & $1.9(0.4-15)$ & .54 \\
\hline Defibrillation & $6 / 173$ & $2.4(0.92-6.3)$ & .07 & $2.3(0.88-6.1)$ & .09 \\
\hline Ventricular pacing & $3 / 42$ & $5.2(1.4-19)$ & .01 & $5.0(1.4-18)$ & .01 \\
\hline
\end{tabular}

Values in bold are statistically significant at $P<.05$. PoAF, Postoperative atrial fibrillation; $N$, number of patients; $O R$, odds ratio; $C I$, confidence interval; $C A B G$, coronary artery bypass graft; $C A B G+$ valvular, combination of $C A B G$ and valvular surgery; $C A B G+$ valvular + , surgeries involving $C A B G$, valvular, and at least 1 other type of cardiac procedure. *Association between surgery characteristics and incidence of MACE were assessed via multivariable logistic regression. Covariates were included via backward stepwise selection $(P$ exclusion $=.20, P$ inclusion $=.10)$, with forcing of age, sex, and race, and model-based selection of country BMI, smoking, hypertension, heart failure, renal failure, COPD, history of Afib, prior PCI, perioperative use of antiarrhythmics, statin, anticoagulant, and beta-blocker use. $\nmid P$ trend across the categories of surgery type as ordered in the Table (OR [95\% CI] for linear trend was 0.96 [0.66-1.4]). $\ddagger$ Use of pump (ie, off pump vs on-pump) is essentially a distinction within category of CABG alone. $\S \mathrm{OR}$ for offpump versus on-pump not estimable because there was no event in the off-pump group. $\|$ OR represents change in odds per 10-minute increase in duration. $\mid$ Indicates the number of patients with nonmissing value for the variable. $\# P$ trend across the categories of rhythm return method as ordered in the table (OR [95\% CI] for linear trend was $1.5[1.1-2.1])$. 
TABLE E5. Postoperative atrial fibrillation and incidence of mortality, as well as resource use among patients undergoing cardiac surgery in the OPERA trial

\begin{tabular}{|c|c|c|c|c|c|}
\hline \multirow[b]{2}{*}{ End points } & \multirow[b]{2}{*}{ No. of cases of death/Total N (\%) } & \multicolumn{2}{|c|}{ Univariate model } & \multicolumn{2}{|c|}{ Multivariable model* } \\
\hline & & HR $(95 \%$ CI $)$ & $P$ value & HR $(95 \%$ CI $)$ & $P$ value \\
\hline \multicolumn{6}{|l|}{ Mortality at $30 \mathrm{~d}$} \\
\hline Without PoAF & $13 / 1002(1.3)$ & reference & & reference & \\
\hline With PoAF & $10 / 460(2.2)$ & $1.6(0.70-3.3)$ & .29 & $1.4(0.60-2.7)$ & .59 \\
\hline \multicolumn{6}{|l|}{ Mortality at $1 \mathrm{y}$} \\
\hline Without PoAF & $22 / 1002(2.2)$ & reference & & reference & \\
\hline With PoAF & $24 / 460(5.2)$ & $2.5(1.4-4.5)$ & .002 & $2.2(1.2-3.9)$ & .01 \\
\hline Length of ICU/CCU stay, $\mathrm{d} \dagger$ & $1205 \ddagger$ & $0.69(0.43-0.95)$ & $<.001$ & $0.62(0.35-0.88)$ & $<.001$ \\
\hline Total length of hospital stay, $d \dagger$ & 1516 & $1.3(0.71-1.9)$ & $<.001$ & $1.1(0.47-1.7)$ & .001 \\
\hline
\end{tabular}

Values in bold are statistically significant at $P<.05 . N$, number of patients; $H R$, hazard ratio; $C I$, confidence interval; $P o A F$, postoperative atrial fibrillation; $I C U$, intensive care unit; $C C U$, Coronary care unit. *Association between PoAF and mortality was assessed via Cox proportional hazard model. Covariates were included via backward stepwise selection $(P$ exclusion $=.20, P$ inclusion $=.10)$, with forcing of age, sex, and race, and model-based selection of country, BMI, smoking, hypertension, heart failure, renal failure, COPD, history of Afib, prior PCI, perioperative use of antiarrhythmics, statin, anticoagulant, and beta-blocker use. Likewise, association between postoperative atrial fibrillation and length of stay was assessed via multivariable-adjusted linear regression. †Estimates represent average difference in duration comparing patients with PoAF to those without PoAF. ‡Indicates the number of patients with nonmissing value for the variable. 
TABLE E6. Independent predictors of duration of ICU/CCU stay among patients undergoing cardiac surgery in the OPERA trial*

\begin{tabular}{|c|c|c|}
\hline Predictors & $(\mathbf{9 5} \% \mathbf{C I}), \mathbf{d} \dagger$ & $P$ value \\
\hline Age & $0.16(0.06-0.27) \ddagger$ & .002 \\
\hline Female & $0.25(-0.05$ to 0.48$)$ & .09 \\
\hline \multicolumn{3}{|l|}{ Country } \\
\hline Italy & reference & \\
\hline USA & $0.59(0.29-0.89)$ & $<.001$ \\
\hline Argentina & $1.4(1.0-1.6)$ & $<.001$ \\
\hline Prior history of Afib & $-0.28(-0.79$ to 0.22$)$ & .27 \\
\hline COPD & $0.49(0.13-0.85)$ & .008 \\
\hline Chronic renal failure & $0.74(0.27-1.2)$ & .002 \\
\hline Congestive heart failure & $0.60(0.31-0.89)$ & $<.001$ \\
\hline BMI & $-0.02(-0.03$ to 0.001$)$ & .08 \\
\hline baseline use of anti-arrhythmics & $0.24(-0.11$ to 0.59$)$ & .19 \\
\hline Perioperative use of beta-blocker & $-0.56(-0.81$ to -0.31$)$ & $<.001$ \\
\hline Perioperative use of statin & $-0.40(-0.65$ to -0.15$)$ & .01 \\
\hline Type of surgery & & $.13 \S$ \\
\hline CABG & reference & \\
\hline Valvular & $-0.04(-0.34$ to 0.25$)$ & .77 \\
\hline $\mathrm{CABG}+$ valvular & $0.28(-0.13$ to 0.69$)$ & .18 \\
\hline $\mathrm{CABG}+$ valvular + & $0.31(-0.57$ to 1.2$)$ & .49 \\
\hline Minithoracotomy & $-0.39(-0.92$ to 0.13$)$ & .14 \\
\hline Use of cardioplegia & $0.14(-0.22$ to 0.49$)$ & .46 \\
\hline Assisted rhythm return & $0.35(0.01-0.62)$ & .007 \\
\hline PoAF & $0.44(0.18-0.71)$ & .001 \\
\hline MACE & $1.9(1.2-2.7)$ & .001 \\
\hline
\end{tabular}

Values in bold are statistically significant at $P<.05$. CI, Confidence interval; $A f i b$, atrial fibrillation; $C O P D$, chronic obstructive pulmonary disease; $B M I$, body mass index; $C A B G$, coronary artery bypass graft; $C A B G+$ valvular, combination of $\mathrm{CABG}$ and valvular surgery; $C A B G+$ valvular + , surgeries involving $C A B G$, valvular, and at least 1 other type of cardiac procedure; $P O A F$, postoperative atrial fibrillation; $M A C E$, major in-hospital adverse cardiovascular event. *Evaluation for independent predictors was assessed by including all these variables (with $P<.2$ in a univariate analysis with atrial fibrillation) in a single model. Other variables considered but not included due to $P>.2$ in univariate analysis include race, cardiopulmonary bypass, use of pump heart failure, previous PCI, and left atrial diameter. Subgroup variables in Table 2-valve type, number of bypass grafts, off-pump versus onpump CABG, pump duration, cross duration, cardioplegia dose, number of cardioplegia dose, and cardioplegia approach — were not considered for inclusion in the predictive model because including them would restrict analysis to only patients within the subgroup. $\dagger$ Represents difference in ICU stay per unit increase in continuous variable or compared with the reference for categoric variable. †Estimate represents change in ICU days per 10-year increase in age. $\S P$ trend across the categories of surgery type as ordered in the Table. 
TABLE E7. Independent predictors of total hospital stay among patients undergoing cardiac surgery in the OPERA trial*

\begin{tabular}{|c|c|c|}
\hline Predictors & $(95 \% \mathrm{CI}), \mathbf{d} \dagger$ & $P$ value \\
\hline Age & $0.39(0.14-0.64) \ddagger$ & .002 \\
\hline Female & $0.26(-0.40$ to 0.92$)$ & .44 \\
\hline \multicolumn{3}{|l|}{ Country } \\
\hline Italy & reference & \\
\hline USA & $-47(-1.2$ to 0.30$)$ & .24 \\
\hline Argentina & $0.42(-0.35$ to 1.2$)$ & .28 \\
\hline Prior history of Afib & $-0.11(-0.52$ to 0.30$)$ & .61 \\
\hline COPD & $0.35(0.04-0.766)$ & .03 \\
\hline Chronic renal failure & $0.79(0.40-1.2)$ & $<.001$ \\
\hline Congestive heart failure & $0.42(0.19-0.65)$ & $<.001$ \\
\hline Left atrial diameter & $0.09(-0.06$ to 0.25$) \ddagger$ & .23 \\
\hline baseline use of anti-arrhythmics & $0.51(0.04-0.98)$ & .03 \\
\hline Perioperative use of beta-blocker & $-0.32(-0.52$ to -0.11$)$ & .002 \\
\hline Perioperative use of statin & $-0.21(-0.43$ to 0.001$)$ & .19 \\
\hline Type of surgery & & $.13 \S$ \\
\hline CABG & reference & \\
\hline Valvular & $0.11(-0.13$ to 0.36$)$ & .37 \\
\hline CABG + valvular & $0.27(-0.08$ to 0.62$)$ & .14 \\
\hline CABG + valvular + & $0.28(-0.48$ to 1.0$)$ & .47 \\
\hline Minithoracotomy & $-0.45(-0.86$ to 0.04$)$ & .03 \\
\hline Use of cardioplegia & $0.93(0.44-1.4)$ & $<.001$ \\
\hline Cardiopulmonary bypass & -0.04 ( -0.61 to 0.52$)$ & .88 \\
\hline Assisted rhythm return & $0.52(0.31-0.74)$ & $<.001$ \\
\hline PoAF & $0.69(0.47-0.90)$ & $<.001$ \\
\hline MACE & $0.80(0.11-1.5)$ & .02 \\
\hline
\end{tabular}

Values in bold are statistically significant at $\mathrm{P}<.05$. CI, Confidence interval; $A$ fib atrial fibrillation; $C O P D$, chronic obstructive pulmonary disease; $C A B G$, coronary artery bypass graft; $C A B G+$ valvular, combination of $C A B G$ and valvular surgery; $C A B G+$ valvular + , surgeries involving CABG, valvular, and at least 1 other type of cardiac procedure; $P O A F$, postoperative atrial fibrillation; MACE, major inhospital adverse cardiovascular event. *Evaluation for independent predictors was assessed by including all these variables (with $P<.2$ in a univariate analysis with atrial fibrillation) in a single model. Other variables considered but not included because of $P>.2$ in univariate analysis include race, hypertension, BMI, heart failure, and previous PCI. Subgroup variables in Table 2-valve type, number of bypass grafts, offpump versus on-pump CABG, pump duration, cross duration, cardioplegia dose, number of cardioplegia dose, and cardioplegia approach — were not considered for inclusion in the predictive model because including them would restrict analysis to only patients within the subgroup. $\dagger$ Represents difference in total hospital days per unit increase (for continuous variables) or compared with the reference (for categoric variable). $\ddagger$ Estimate represents change in total hospital days per 10-unit increase (ie, 10 years for age and $10 \mathrm{~mm}$ for left atrial diameter) in the variable. $\S P$ trend across the categories of surgery type as ordered in the Table. 
TABLE E8. New-onset postoperative atrial fibrillation requiring treatment and incidence of mortality among patients undergoing cardiac surgery in the OPERA trial

\begin{tabular}{|c|c|c|c|c|c|}
\hline \multirow[b]{2}{*}{ End points } & \multirow[b]{2}{*}{ No. of cases of death/Total $N(\%)$} & \multicolumn{2}{|c|}{ Univariate model } & \multicolumn{2}{|c|}{ Multivariable model* ${ }^{*}$} \\
\hline & & $\overline{\text { HR }(95 \% \text { CI })}$ & $P$ value & $\overline{\text { HR }(95 \% \mathrm{CI})}$ & $P$ value \\
\hline \multicolumn{6}{|l|}{ Mortality at $30 \mathrm{~d}$} \\
\hline Without $\mathrm{PoAF}_{\mathrm{NT}}$ & $13 / 1003(1.3)$ & reference & & reference & \\
\hline With $P_{0 A F_{N T}}$ & $10 / 311(3.1)$ & $2.4(1.1-5.6)$ & .03 & $3.1(1.2-7.8)$ & .02 \\
\hline \multicolumn{6}{|l|}{ Mortality at $1 \mathrm{y}$} \\
\hline Without PoAF $F_{N T}$ & $22 / 1003(2.2)$ & reference & & reference & \\
\hline With PoAF ${ }_{N T}$ & $20 / 311(6.4)$ & $2.5(1.1-5.7)$ & .02 & $3.2(1.2-8.4)$ & .01 \\
\hline
\end{tabular}

Values in bold are statistically significant at $P<.05 . N$, Number of patients; $H R$, hazard ratio; $C I$, confidence interval; $P o A F_{N T}$, new-onset postoperative atrial fibrillation requiring treatment. *Association between $\mathrm{PoAF}_{\mathrm{NT}}$ and mortality was assessed via Cox proportional hazard model. Covariates were included via backward stepwise selection $(P$ exclusion $=.20, P$ inclusion $=.10$ ), with forcing of age, sex, and race, and model-based selection of country, BMI, smoking, hypertension, heart failure, renal failure, COPD, history of Afib, prior PCI, perioperative use of antiarrhythmics, statin, anticoagulant, and beta-blocker use. Likewise, association between postoperative atrial fibrillation and length of stay was assessed via multivariable-adjusted linear regression. 